\title{
Article \\ A VR-Enabled Chatbot Supporting Design and Manufacturing of Large and Complex Power Transformers
}

\author{
Amy J. C. Trappey ${ }^{1, *}$, Charles V. Trappey ${ }^{2}{ }^{\mathbb{D}}$, Min-Hua Chao ${ }^{1}{ }^{\mathbb{D}}$, Nan-Jun Hong ${ }^{1}$ and Chun-Ting Wu ${ }^{1}$ \\ 1 Department of Industrial Engineering and Engineering Management, National Tsing Hua University, \\ Hsinchu 300, Taiwan; s106034803@m106.nthu.edu.tw (M.-H.C.); s107034531@m107.nthu.edu.tw (N.-J.H.); \\ s108034530@m108.nthu.edu.tw (C.-T.W.) \\ 2 Department of Management Science, National Yang Ming Chiao Tung University, Hsinchu 300, Taiwan; \\ trappey@nycu.edu.tw \\ * Correspondence: trappey@ie.nthu.eu.tw; Tel.: +886-3572-7686
}

check for updates

Citation: Trappey, A.J.C.; Trappey, C.V.; Chao, M.-H.; Hong, N.-J.; Wu,

C.-T. A VR-Enabled Chatbot

Supporting Design and

Manufacturing of Large and

Complex Power Transformers.

Electronics 2022, 11, 87

https://doi.org/10.3390/

electronics11010087

Academic Editors: Răzvan

Gabriel Boboc, Radu Godina,

Albert Smalcerz and

Dimitris Mourtzis

Received: 14 December 2021

Accepted: 24 December 2021

Published: 28 December 2021

Publisher's Note: MDPI stays neutral with regard to jurisdictional claims in published maps and institutional affiliations.

Copyright: (C) 2021 by the authors. Licensee MDPI, Basel, Switzerland. This article is an open access article distributed under the terms and conditions of the Creative Commons Attribution (CC BY) license (https:// creativecommons.org/licenses/by/ $4.0 /)$.

\begin{abstract}
Virtual reality (VR) immersive technology allows users to experience enhanced reality using human-computer interfaces (HCI). Many systems have implemented VR with improved HCI to provide strategic market advantages for industry and engineering applications. An intelligent chatbot is a conversational system capable of natural language communication allowing users to ask questions and receive answers online to enhance customer services. This research develops and implements a system framework for a VR-enabled large industrial power transformer masscustomization chatbot. The research collected 1272 frequently asked questions (FAQs) from a power transformer manufacturers' knowledge base that is used for question matching and answer retrieval. More than 1.2 million Wikipedia engineering pages were used to train a word-embedding model for natural language understanding of question intent. The complex engineering questions and answers are integrated with an immersive VR computer human interface. The system enables users to ask questions and receive explicit and detailed answers combined with 3D immersive images of industrial sized power transformer assemblies. The user interfaces can be projected into the VR headwear or computer screen and manipulated with a controller. The unique immersive VR consultation chatbot system is to support real-time design consultation for the design and manufacturing of complex power transformers.
\end{abstract}

Keywords: intelligent chatbot; virtual reality; smart manufacturing; power transformer

\section{Introduction}

Large-size industrial power transformers are complex static engineering systems used for electrical power distribution to step-up voltages for transmission from power plants or distribution centers and step-down voltage levels for receiving power at end user factories, manufacturing centers, or large building complexes. A high degree of customization is required for complex industrial-grade machinery design and manufacturing of transformers due to their extensive use in all aspects of construction including large ships, wind farms, factories, large medical centers, and even shopping malls. In order to provide remote customers with highly customized machinery designs and quotations, engineering consultation services during the processes of procurement are critically important. This research develops a generic methodology and system framework for building a Virtual Reality (VR) enabled intelligent engineering consultation Chatbot system. The customer-driven transformer consultation Chatbot prototype with VR as an improved Human Computer Interface (HCI) is demonstrated using a case example in Section 4.

Request for Quotation (RFQ) is a process where an enterprise or public entity releases purchase specifications for the manufacturing, design, and services for a product or service to a qualified vendor. Vendors then tender bids in response to the request, which often requires interaction and negotiations over key components, customization, services, and 
price before a vendor is selected. For non-customized products and systems, the buyer may opt to use closed bids from vendors without negotiation or consultation of design and price. The purpose of an RFQ is to provide suppliers with the specifications of the procurement item such that price quotations and warrantees for their product and services may be formulated. An RFQ generally includes the product description, quantity, delivery date, delivery location, contact person, unit price range, and whether alternative components may be used in the design. The composition of the RFQ bid must be supported by engineering knowledge data, including a Bill of Materials (BOM), manufacturing process, cost estimation, guarantees and warranties, transportation, installation, and safety inspection [1]. For manufacturers, archived RFQs are high value engineering knowledge documents that are managed to strengthen communications with current and future industrial customers. An RFQ is a less structured text and figure-based document with design features and tables that are created from the buyer's domain knowledge. The buyer's knowledge may not be current with what the supplier can provide since suppliers must continuously conduct research to improve the design and lower costs to better satisfy a prospective buyer's requirements. For large power transformers, there are few closed bids since the seller should be able to pitch their bid and explain the strategic advantage of the price, product, and service based on their latest technology and be allowed to negotiate the terms and designs to reach a solution. The vendor that provides an advanced transparent solution with the fewest issues on time and within the price range will most likely win the bid. For the specification and design confirmation stage of large-scale industrial products such as transformers, customization is widely adopted, which means that close and frequent communication between manufacturers and customers is necessary. In order to quickly answer customers' technical questions and provide $24 / 7$ service, a Chatbot was built into the customization stage. For this research, RFQ knowledge documents are treated as the core knowledge content for training and verifying the consultation Q\&A Chatbot.

A key concept in advanced Chatbot development is to improve the buyer's experience, especially for complicated engineering products and services involving negotiated procurement bids. In the past, enterprise customer service was a manual task requiring text messages, site sales visits, and numerous phone calls. Sellers often have insufficient and inexperienced service staff, operate under high costs, and provide poor quality service that results in frequent customer complaints and loss of sales. Over the last decade, there has been an increased need to improve service quality to maintain strategic market advantage. A result of this trend has been implementation of software as service Chatbots or "virtual assistants" across many industrial sectors [2]. For engineering or manufacturing companies, customer service Chatbot development faces many challenges due to insufficient domain specific knowledge required for building consultation Chatbots. Knowledgeable Chatbots require high level professional linguistic capabilities to understand technical questions and provide correct answers. Intelligent consultation Chatbots are especially important for manufacturers of complex machineries to properly answer global customers' technical questions online at any time.

For large and complex power transformers, the immersive visualization capability of a Chatbot is also needed to provide a vivid illustration of the design offered during Chatbot Q\&A. Through the user's actions in reality and the information transmitted to the virtual world, VR creates the interaction between people and the realistic virtual space with an immersive experience, thereby demonstrating great potential for various application scenarios [3]. As reported by literature sources [4], VR technology is the core information technology for enhancing the HCI of industrial applications used for complicated engineering modelling and intelligent manufacturing. When VR is applied to industrial training, immersion improves worker efficiency as well as safety. The combination of VR and digital twins constructs digital mirror images of 3D objects in the physical world and moves the images into virtual space. The virtual image becomes the basis for applications supporting product design, manufacturing, and commercial promotion. 
In this study, an immersive interactive environment is created for the functions of component design, assembly, and disassembly in the process of customization of largescale industrial transformers. Before the 3D model is built, a $2 \mathrm{D}$ engineering design layout is needed to construct a complete model that meets the desired specifications. Before the power transformer is built, the manufacturer of power transformers needs to provide an approval drawing to the customer. The approval drawing includes the transformer outline drawing, nameplate, and specification. In view of this, when the model is under construction, the structure of the approval drawing and related important equipment need to be included. The 3D product design when compared with only 2D images before manufacturing provides customers with a better visual presentation to enhance understanding of the product and to make discussions more efficiently.

Using the proposed system, the appearance and structure of industrial power transformer are presented to customers in VR interactive fashion before the RFQ document was proposed to accelerate the customization process, and customers' questions can be answered by Chatbot with knowledge related to engineering specification, bill of material, and cost estimation about transformers. In this paper, the following objectives are achieved:

1. Build a retrieval-based chatbot with knowledge base containing conversation (Q\&A) dataset, international standards document set, transformer components, and cost information.

2. Train a word embedding model and construct a similarity calculation module for chatbot information retrieval.

3. Construct a Virtual Reality environment that provides transformer 3D models and user interactions.

4. Combine a chatbot with immersive VR HCI and demonstrate the system interface.

The paper is structured as follows. In Section 2, the literature review introduces power transformer knowledge, Chatbot technologies with natural language processing (NLP) capabilities, and VR immersive technology and applications for advanced manufacturing. Section 3 describes the VR-enabled Chatbot system development process flow and the application methodologies such as Chatbot FAQ knowledge training, Q\&A matching and retrievals, BoM-based transformer cost estimation, VR environment building, and the integration of system modules. Using the complex transformer engineering design and consultation process as the case example, the VR-enabled Chatbot prototype is described, and system scenarios are tested. The performance measurements and verification are presented in Section 4. The final conclusions and the contributions of the research are presented in Section 5.

\section{Literature Review}

In this section, the literature of related domain knowledge of power transformers and the methodologies for Chatbots, NLP, VR immersive technologies for applications in collaborative design, manufacturing, and customer support are reviewed.

\subsection{Power Transformers}

Transformers play an important role in power conversion and transmission in the electrical distribution system. The main functions are for voltage conversion, current conversion, impedance transformation, isolation, and voltage regulation (magnetic saturation transformer), enabling the transformer to increase or decrease different voltage levels depends on changing the number of windings on each side [5]. Trappey, et al. [6], used an intelligent text mining approach to create an ontology of power transformers (Figure 1) that is divided into three parts: material, function, and connectivity. 


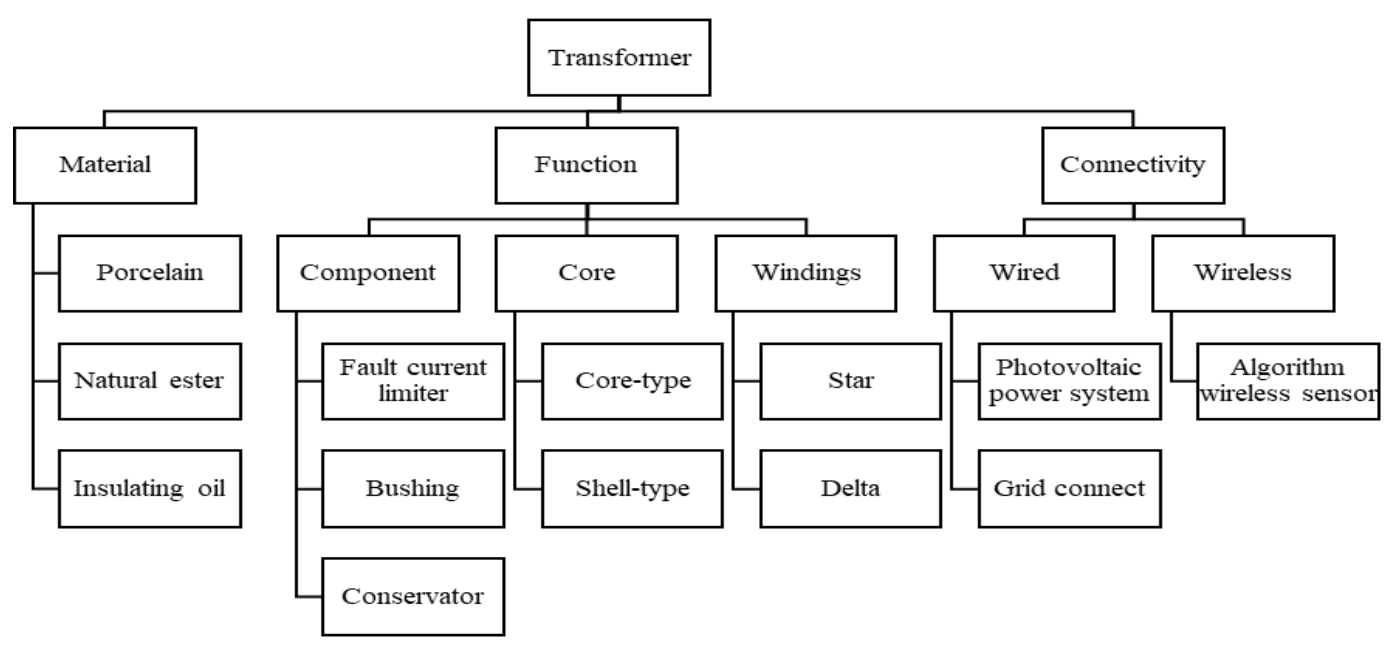

Figure 1. Ontology schema of power transformer design and manufacturing.

To construct a power transformer for a perspective client, engineers first need to read the RFQ. RFQ often used for mass customized products where multiple suppliers read the specifications, provide an engineering drawing of the configuration, a Bill of Materials, and augmented services (if required) including the price bid [7]. The customer RFQ details the product specifications, quality requirements, expected applications, verification methods, shipping packaging, international compliance standards, delivery quantity, and shipping date that is sent to their preferred suppliers. Next, the supplier must show the compliance level of the product in sequence according to the major requirements of the customer, or propose a better solution, with the most competitive pricing. Power transformers are highly customized products and satisfying the clients requirements requires experienced engineers to calculate the required core size, the turns, dimensions and electrical characteristics of the coil conductor (efficiency, voltage variation rate, excitation, magnetic current, impedance voltage and other characteristics).

\subsection{Chatbot}

Chatbots enable friendly human-computer conversations by delivering real-time intelligent Q\&A services and simulate communication between the system and the user [8]. ELIZA was the first Chatbot developed in 1966 at Massachusetts Institute of Technology (MIT), which inspired the construction of future Chatbots [9]. The Chatbot places the inquiry on the decision tree at a given level that makes transferring the discourse to a human for a quick response more efficient [10]. Chatbot related products such as Amazon Alexa, Google Assistant and Apple Siri have continued to emerge, and have become a part of people's lives in the digital world [11]. Based on different design techniques, Chatbots are classified as rule-based and AI-based. AI-based Chatbots are further classified as retrievalbased and generative-based as shown in Figure 2 [12]. Rule-based Chatbots are constructed using pre-scripted dialogs, which provide answers according to predefined rules, and are less intelligent and lack of learning capability. The benefit is that the construction cost is low and acceptable results can be realized if the script is written sufficiently and creatively [10]. Retrieval-based methods use NLP techniques to efficiently select proper responses from existing conversational data and generate responses using natural language generation models [13]. 


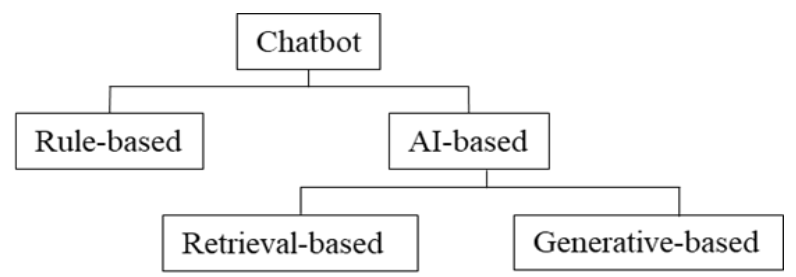

Figure 2. Classification of chatbots based on design techniques.

The literature in recent years shows that Chatbots are widely used in the field of e-commerce as an automated virtual customer assistant. $\mathrm{Xu}$, et al. [14] proposed a Chatbot that uses social media to request and accept customer service and showed that the Chatbot outperformed an information retrieval system. To be able to provide consulting services in a specific field, Frequently Asked Questions (FAQs) are commonly used as the knowledge base. Jang and Lee [15] proposed a dialogue-based Question and Answer (Q\&A) system based on an ontology to replace the traditional FAQ list. Their research shows that adding the ontology constructed by Word2Vec to the question answering system enhances usability. Gapanyuk, et al. [16] developed a hybrid Chatbot system based on Q\&A and knowledge base methods, which creates an automatic consultant to answer detailed questions such as product features and assist customers in choosing products. Doc2Vec and TF-IDF are used in Q\&A text vectorization, and deep learning technology is used to process the knowledgebase. Nayak, et al. [17] used TF-IDF combined with the n-gram model and NLP technology to provide an Adaptive Manager on Duty Chatbot for cloud-based architectures. Through the above review, Word2Vec and TF-IDF with NLP modules are frequently used and are selected as the basis of the Q\&A Chatbot in this research.

Patent documents are also used to find the main technologies applied in Chatbots [18]. As an intangible asset, patent documents are widely used in business. Through patent analysis, there are many methods to structure and understand the specific knowledge domain using algorithms. Through analysis, patents can provide references for decisionmaking in the development of technology, products and services. Patent analysis provides important development information for a company by providing useful information for developing technology strategies and assessing competitor's product advantages. Hong, et al. [19] presented an advanced approach to generate a patent map that is called the Technology Function Product Matrix. This research uses the generated matrix to analyze the dialog system technology of Chatbots and presents the distributions of key technologies, functional improvements, and novel applications. Table 1 shows five patent development trends related to Chatbot dialog systems. Chatbot related patents focus on intent detection and domain identification. Intent detection is a technology that uses text mining algorithms and detection rules to detect user intention. The results show embedded device and natural language understanding (NLU) are the current technology developments. NLU is a method where systems assume what a speaker actually means and better enables the Chatbot to understand the users' messages and provide more satisfying answers. Further product application applies dialogue function analysis to an embedded system. From the analysis of the identified technology trends, the patent data show that companies around the world are rapidly developing Chatbot technologies. AT\&T Inc., IBM, Microsoft and Stanford research are the leading assignees developing Chatbot technologies. 
Table 1. Top five patent technology trends of Chatbot dialog systems.

\begin{tabular}{cc}
\hline Technology Sub-System/Function or Product & Patent Count \\
\hline Intent detection/Embedded device & 141 \\
\hline Domain identification/Embedded device & 122 \\
\hline Intent detection/Natural language understanding & 114 \\
\hline Content planning/Embedded device & 113 \\
\hline Domain identification/Natural language understanding & 109 \\
\hline
\end{tabular}

\subsection{Natural Language Processing (NLP)}

NLP is an application using advanced information technology (AI, machine learning, text mining) to compile and analyze natural language data in order to improve interactions between computers and users [20]. In a Chatbot, NLP is used to understand user input and the question must be converted into a form that the computer or system can read in order to perform subsequent information retrieval and question answering. Word embedding technologies, e.g., Word2Vec and Doc2Vec, are the core NLP models adopted in Chatbots.

Word embedding is a method of converting natural language into data vectors that can be the input of machine learning algorithms. The retrieved word vector method helps identify similar contexts from a given word [21]. Among the most commonly used word embedding models are one-hot representation and distributed representation models. Onehot representation uses a long vector to represent words. The length of the vector is the size of the dictionary. Each vector has a dimension of 1 or 0 . The dimension 1 indicates the position of the word in the dictionary [22]. Bengio, et al. [23] formally proposed the Neural Network Language Model (NNLM), which creates word vectors while training the language model. Word embedding is also known as distributed representation, which is a collective term for language models and feature learning techniques in NLP. NNLM maps the high-dimension word vector (one-hot representation) of each word into a smaller dimensional vector and places all the vectors together to form a word vector space with each vector representing a point in space. In the vector space, the lexical or semantic similarity between words, according to the distance between both vectors, is calculated. Word embedding uses neural networks, probabilistic models, and explicit representations of the context in which a word is located. Word2Vec [24] is applied in this research, while more sophisticated algorithms can be tested and adopted for future research. The speed of Word2Vec model training is faster than other models and has become the most popular word embedding method. Word embedding improves the performance of NLP tasks such as semantic and sentiment analysis.

The Word2vec algorithm is trained using a large amount of text data where words are represented by their mathematical meaning in the form of high dimension vectors. After embedding words in vector space, words with similar semantics are identified since they are closer to one another in the vector space. Two important models in word embedding are the continuous bag-of-words (CBOW) model and the continuous skip-gram model. Figure 3 shows the schematic diagram of skip-gram and CBOW models. The CBOW model uses context to predict the probability of the current word, while skip-gram uses the current word to predict the probability of its context. The major difference is that skip-gram is better for infrequent words than $\mathrm{CBOW}$. CBOW finds the word with maximum probability for the context, which may cause issues for words that infrequently appear in a given context and will assign these words a low probability. Skip-gram learns to predict the context from a given word. Two words (one infrequent and the other frequent) are treated the same. Both are treated as word and context observations enabling the model to learn infrequently used words. 


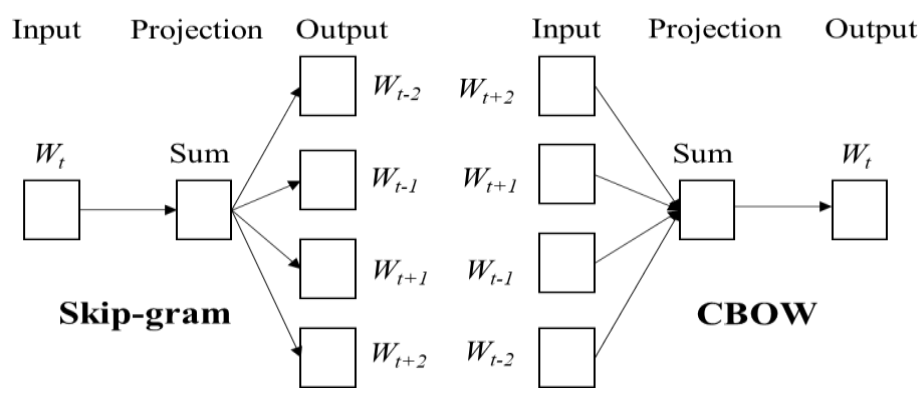

Figure 3. The schematic diagram of skip-gram and CBOW models.

\subsection{Virtual Reality (VR)}

VR technology enables users to experience the virtual environment while interacting with the system [25]. Bamodu and Ye [26] provide an early but detailed introduction of VR hardware and software technologies that led to new incremental advances. They divided hardware into computers and the VR engine and input and output devices. Software was divided into application software and databases (see Figure 4). For VR hardware, tracking devices, point input devices, bio-controllers, and voice devices enable users to interact with the virtual environment. The output devices provide users with an appropriate response in real time by sending a signal to the system about the user's command actions. The VR engine requires high level computer function capabilities for processing visual data. The computer must be capable of recalculating the visual display in a virtual environment approximately every 33 milliseconds and produce real time and high-quality simulations at the rate of more than 24 frames per second [25]. VR software provides platforms for developers to design and construct virtual interaction environments and provides the databases used to store the corresponding information. The software tools are classified as modeling tools and development tools. Modeling software is used to build models or components used in the 3D environment. There are many different tools available for 3D modeling. Commonly used tools for engineering applications include Autodesk, CATIA and SolidWorks. The choice of the appropriate VR development tools and software packages, e.g., Unity 3D, CryEngine, Unreal Engine, and Lumberyard, requires analysis to evaluate the flexibility of features offered by these packages, interface compatibility, file formats, the ease of creating animations, collision detection, and the input and output devices used by the intended community of users [26].

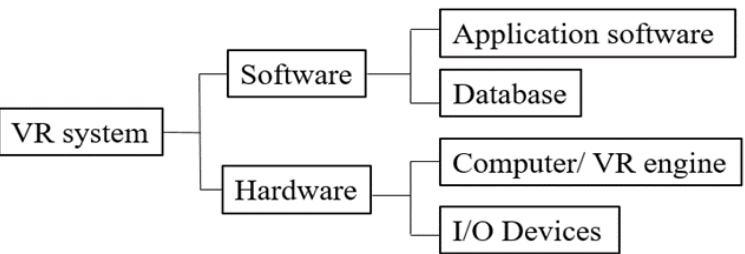

Figure 4. VR software and hardware.

To provide users with a stronger sense of immersion, 360-degree VR has developed rapidly. Existing efforts to improve the streaming media experience focus on the client adaptive bitrate (ABR) algorithm [27]. Hayes and Chang [28] proposed a unique multi-path aware peer-to-peer (P2P) method, which is able to support 360-degree VR media streams efficiently by removing the limitations of client-side ABR in multipath networks. This approach eliminates the need to rely on error-prone network models or suboptimal client heuristics. To observe the behavior of users watching 360-degree videos, data collected from users are investigated and provided publicly helping researchers study 360-degree video consumption [29].

In addition to visual enhancement, many studies have incorporated other senses in VR to enhance immersive feelings [30]. Three-dimensional sound technology based on 
the head related transfer function (HRTF) has limits reproducing realistic sounds because the environment is projected in virtual space and an artificial sense of sound results in a disconnect from reality [31]. The sound propagation and sound generating steps are the most important steps for improving the feeling of immersion [32]. There are technical possibilities of creating haptic feedback for a feeling of touch but consumer-level VR systems have limited technical development. Most systems include and utilize the possibility of generating tactile feedback through vibration but costs increase when adding feedback systems and external mechanical hardware to produce the sensation of touch. Rietzler, et al. [33] described a method of creating haptics by using unmodified off-the-shelf hardware and a software solution for multi-modal pseudo-haptic methods. Visual and tactile cues that transmit kinesthetic feedback and induce user perception significantly improve the entertainment and a feeling of presence in the VR environment. Nam and Kwon [34] designed an interface for digital drawing that can control a five-finger tactile controller in VR. The haptic controller interface module measures the pressure from each finger unit, controls the movement of the linear actuator, and provides haptic feedback in the form of vibration.

\subsection{VR Applications for Engineering Design and Manufacturing}

VR applications for engineering design and manufacturing have increased significantly since 2017 [35]. VR and augmented reality (AR) technologies have provided many different applications, such as manufacturing planning, process simulation, product design, product testing, modelling, and employee training [36]. Gonzalez-Badillo, et al. [37] describe a VR haptic enabled platform that provides an environment to design, plan and evaluate virtual manufacturing assemblies of components, and allow engineers to manipulate and interact with virtual components in real-time. Peng, et al. [38] present a VR system for interactive modular fixture configuration and apply a multi dimension modular fixture assembly model to enhance visualization and management. The proposed 3D manipulation approach improves intuitive interaction and yields greater accuracy in positioning components. Guo, et al. [39] describe a complete maintenance design process that integrates VR to improve the designer's understanding of the product for maintenance planning.

One of the first manufacturing applications of VR was a simulation tool developed in the 1960s [40]. Applications have spread across industries and domains, ranging from gaming, entertainment, engineering, education, and product design. Many virtual environments such as CAVE, enable users to convert 2D images to 3D virtual and immersive environments [41]. The advances of VR technologies have many different engineering applications. VR has been widely accepted by the manufacturing industry [36] for manufacturing planning [42], process simulation [43], product design and testing, modelling [44], and employee training [45].

VR technologies play an important role in the simulation of advanced 3D humancomputer interactions especially for manufacturing assembly that enables user to interact with virtual objects while completely immersed in the virtual environment. VR technologies are transforming the nature of manufacturing and are rapidly becoming the new user service interface for shop workers, service technicians and engineers. With the help of these technologies, the engineering team can visualize problems and receive visual feedback about the impact of new designs and interact with the virtual environment to solve problems in new ways. VR can be used to simulate a production line, implement changes and various conditions that minimize the impact of accidents on the actual manufacturing system [46]. The quality of product can be improved and accidental production shutdowns can be avoided [47]. The VR applications in manufacturing include design, prototyping, machining, assembly, inspection, planning, training, and simulation. Berni and Borgianni [48] reviewed VR applications in design and categorized each of the collected 86 sources into multiple classes and identified design functions that include design activities traditionally supported by VR. These functions include 3D modelling, virtual prototyping, and product evaluation, co-design and design evaluation during the early design phases 
that explains why integration of chatbots, NLP, and VR immersive technologies are critical for intelligent manufacturing services. These applications can be used to simulate and optimize manufacturing process to reduce production costs and enhance quality. Assembly process planning is a critical aspect of product development for the manufacturing industry. For the power transformer industry, the products are highly customized with demand for a large variety of sizes, configurations, and capacity given each customers' power needs, regional requirements, industry regulations, and certification specifications.

VR-enabled HCIs have gained popularity for computer systems supporting engineering design and manufacturing. Some interesting research publications are reviewed in the sub-section. Arrighi and Mougenot [49] proposed a 3D virtual prototype system that provides a high degree of immersion and control by combining VR tools and tangible user interfaces. The system combines visual, auditory and tactile stimuli to ensure a high degree of immersion and is applied in highly customized home interior design scenarios. In the early stages of the industrial design process, some traditional tools used by industrial designers include sketching, storytelling, mind mapping, character exploration, brainstorming notes, role-playing and field observation. These tools are highly dependent on the designer's imagination or domain knowledge, and it is difficult to visualize design concepts. Velasquez [50] used immersive VR as an effective tool in the early stage of industrial design to capture immersive scenes through 360-degree VR. Designers can continuously replay and review these scenes, which provides a more spacious environment. Malik and Brem [51] proposed the application of VR for digital twins. With hyperscale computing, commoditization of sensor equipment, AR or VR and data analytics platforms, it has become possible to develop time dependent 3D models of complex physical systems. This approach extends the usefulness of virtual models developed in the design phase to the lifecycle of a system.

Lipton, et al. [52] proposed a VR-supported remote-control robot system. By combining the Oculus head-mounted display, Unity VR engine, and Baxter robotic arm, the remote robot can be controlled through the network in the VR environment for assembly operations. This is a case of a VR application in a cyber physical system. This system provides a shared VR control virtual space for users and robots. The user controls the physical robot by operating the digital dual, and the sensors and cameras on the robot can assist in modeling the environment and updating the VR environment through network transmission. Han, et al. [53] proposed a system integration framework for applying VR to the construction of ships and offshore structures, which are also highly complex and large-scale customized industrial products. The study emphasizes the validity and efficiency of VR in model visualization. There are no reported cases where VR is applied to highly customized large power transformers. Gorecky, et al. [54] pointed out that reuse of product and process data is a promising approach to leverage virtual simulation of manual manufacturing processes. Finally, integrating VR and NLP for domain knowledge management and decision support has gained increased research attention. Sermet [55] proposed integrating intelligent knowledge generation with communication systems using VR technologies.

\section{Methodology}

The methodology and framework of three sub-systems are introduced, which are Q\&A chatbot, cost estimation, and VR. In Section 3.1, the collection of FAQs and international standards, the training data preprocessing and modeling for NLP-based conversational understanding, and the Q\&A retrievals are described. Section 3.2 explains the methods of building a BOM-based knowledge base for cost estimations. Section 3.3 describes the VR engine, 3D model building, and the VR environment development for scene design, object control, and applications on the platform. Section 3.4 discusses the system integration of the question answer chatbot, the cost estimation system, and the VR environment.

The theoretical and practical importance of the proposed research is demonstrated by showing the challenges of designing functional VR-based consultation Chatbots that close 
the gap between proposed systems and actual systems being used by a power transformer manufacturer (see Table 2). The framework of the proposed engineering consultation system framework, integrating the NLP-enabled Chatbot, the computer-supported cost estimation, and VR HCI, is shown in Figure 5.

Table 2. Research challenges of the proposed chatbot for complex and highly customized engineering products.

\begin{tabular}{|c|c|c|c|}
\hline Category & Chatbot & Cost Estimation & Virtual Reality \\
\hline Purpose & $\begin{array}{l}\text { User can ask } \\
\text { questions using } \\
\text { sentence expressions } \\
\text { and get answers or } \\
\text { responses } \\
\text { immediately. }\end{array}$ & $\begin{array}{l}\text { Automatic } \\
\text { BOM-based cost } \\
\text { aggregation and } \\
\text { calculation. }\end{array}$ & $\begin{array}{l}\text { User can customize } \\
\text { the product with } \\
\text { immersive views and } \\
\text { tools. }\end{array}$ \\
\hline Advantages & $\begin{array}{l}\text { Instant and global } \\
\text { consultation services. }\end{array}$ & $\begin{array}{l}\text { Accurate BOM-based } \\
\text { cost estimation } \\
\text { including materials } \\
\text { and production costs. }\end{array}$ & $\begin{array}{l}\text { Interaction and } \\
\text { solicitation with a } \\
\text { sense of realistic } \\
\text { scenarios and } \\
\text { component } \\
\text { combinations. }\end{array}$ \\
\hline Limitations & $\begin{array}{l}\text { Questions may not be } \\
\text { fully understood by } \\
\text { the system and may } \\
\text { require an engineer } \\
\text { (person) to be called } \\
\text { into the online } \\
\text { session. }\end{array}$ & $\begin{array}{l}\text { Varied customized } \\
\text { requests may change } \\
\text { the BOM structure } \\
\text { that is difficult to } \\
\text { dynamically integrate } \\
\text { with the ERP modules } \\
\text { with cost-related } \\
\text { databases. }\end{array}$ & $\begin{array}{l}\text { For complex } \\
\text { engineering products } \\
\text { requiring detailed } \\
\text { customization, } \\
\text { consulting services } \\
\text { still require engineers } \\
\text { since the VR } \\
\text { immersive interfaces } \\
\text { do not cover all } \\
\text { aspects of design and } \\
\text { knowledge. }\end{array}$ \\
\hline
\end{tabular}

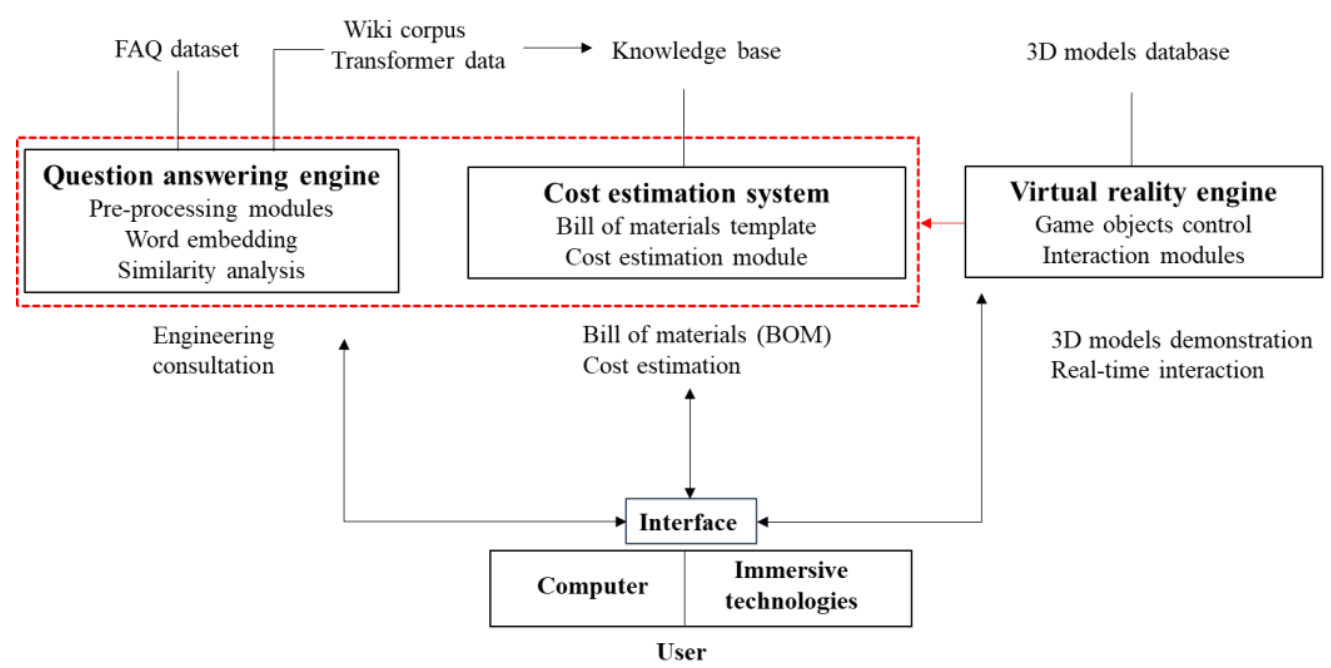

Figure 5. The framework of the NLP-enabled VR-based engineering consultation Chatbot system.

\subsection{Chatbot QEA System}

A retrieval-based Chatbot Q\&A system is adopted in this research by calculating the similarity between the user question and predefined FAQs. The Chatbot eliminates the process of reorganizing the answers and improves the efficiency of the systems accuracy of answers. The process of selecting answers in the FAQ dataset in this research can be divided into the following steps. 
1. Pre-process questions to remove non-informative words and save computing time.

2. Derive word vectors and calculate the similarity between user's question and each question in the FAQ dataset. The answers corresponding to the questions with high similarity will be returned.

Figure 6 shows the proposed Chatbot knowledge base schema in three parts. The first part is the FAQ dataset; the second part is dataset of the mapping of abbreviation and the full name of relative technical terms; and the third part is international standards.

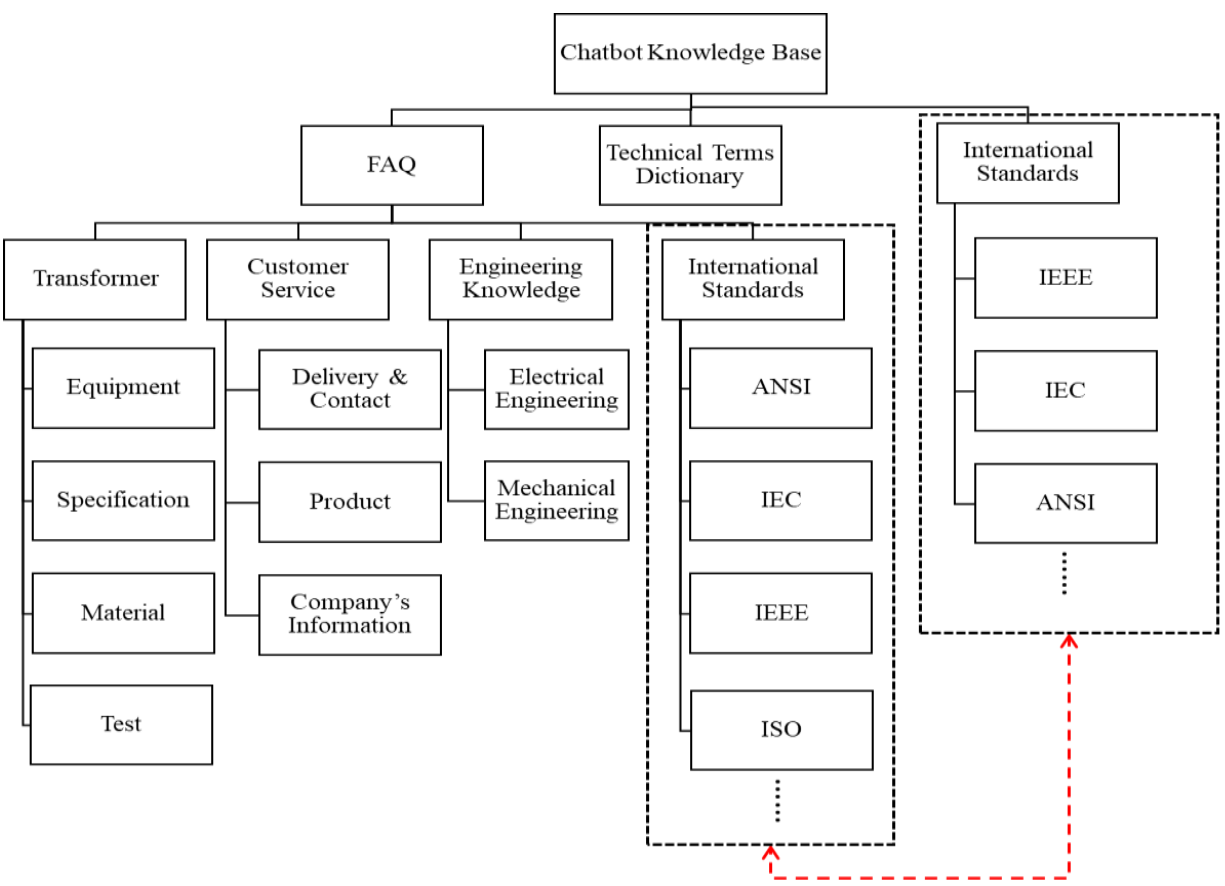

Figure 6. The chatbot knowledge base schema.

The quality of the dataset directly affects the effectiveness of the engineering consultation. The FAQ dataset is collected from the FAQ list on webpages of power transformer suppliers. The questions include many aspects, such as transformer knowledge (equipment, specifications, materials, tests), international standards (ASCI, IEC, ISO), customer support (delivery and contact, product, company information) and engineering knowledge (mechanical engineering, electrical engineering). Engineering domains contains a large number of technical terms, in which abbreviations are collected from technical papers related to power transformers and RFQ files to establish a dataset. For example, HV means high voltage; RTD means resistance temperature detector; and OTI means oil temperature indicator.

Large-scale transformers play an important role in the industry and their design and specifications must comply with different international standards. For example, in IEEE C57.13, the performance requirements for electrical systems and test interchangeability of current and inductively coupled voltage transformers are described. The standard covers the requirements for Class 1 instrument transformers. Customers in this industry may ask suppliers questions about international standards when discussing the design of a power transformer. However, most international standards websites only provide paid document browsing, and do not have sufficient and well-organized FAQ's for users. In order to complement the international standard answering ability in the FAQ dataset, this research collects international standards commonly used in transformer design. These standard and specification files are used to construct a structured database such that users can answer questions related to international standards through the Chatbot interface. Users can search the chapters and contents of standard files related with keywords related to specific parts 
or search the catalogs and preliminary contents of specific standards with standard names and chapters.

The following section explains how to search and retrieve the most relevant answers from the database. During the answer search, similarity analysis is used to calculate the similarity between the questions in the FAQ dataset and the user's question. Before the calculation, each word in a question is converted into a vector, and the word embedding tool used in this system is called Word2Vec [24]. Skip-gram model is used in this study since it can learn better representations for rare words then CBOW. The training data include 5 million articles or more than 40 million pages full text of Wikipedia corpus (https: / / dumps.wikimedia.org/enwiki/, accessed on 24 January 2021), about 1.3 thousand RFQ documents from the power transformer industry, and hundreds of power transformerrelated technical papers retrieved from IEEE. Gensim is used to train the model, which is an open-source Python toolkit for unsupervised learning. There are several parameters that can be chosen in model training. The size is set to 300, which means that the dimension of a word is 300 . The large size requires more training data yielding improved accuracy. The window size is set to five, since a smaller window size gives acceptable results that are syntactically and semantically related and larger windows improve results that require more training time [56]. The word embedding model was obtained after more than eight hours of training, and the number of words in the model's vocabulary is about 1.2 million. After deriving the vectors of every word in a question sentence, the similarity calculation between the user's question and questions in the dataset is conducted. Formula (1) of cosine similarity defines $\mathrm{Ai}$ and $\mathrm{Bi}$ as components of vector $\mathrm{A}$ and vector $\mathrm{B}$ respectively.

$$
\text { Similarity }=\cos \theta=\frac{\sum_{\mathrm{i}=1}^{\mathrm{n}} \mathrm{Ai} * \mathrm{Bi}}{\sqrt{\sum_{\mathrm{i}=1}^{\mathrm{n}} \mathrm{Ai}^{2}} \sqrt{\sum_{\mathrm{i}=1}^{\mathrm{n}} \mathrm{Bi}^{2}}}
$$

Figure 7 describes the process of similarity score calculation and response selection used for searching the FAQ dataset. The process is divided into three steps:

1. Obtain tokenized sentence and convert every word in the sentence into vectors using a trained Word2vec model.

2. Derive the average word vectors of a sentence and calculate the similarity between user's sentence and every sentence in FAQ dataset. For example, when deriving the similarity of the two sentences: $S 1(W 1, W 2, \cdots, W i)$ and $S 2(w 1, w 2, \cdots, w j)$, the first step is to derive the word vectors of each question. $\mathrm{S} 1=(V W 1, V W 2, \ldots, V W i)$, $\mathrm{S} 2=(V W 1, V W 2, \ldots, V W i)$. Then, calculate the average word vectors as a sentence vector: $V_{s} 1=A V G(V W i)$ and $V s 2=A V G(V W j)$. As a result, the similarity of $\mathrm{S} 1$ and $\mathrm{S} 2$ will have the cosine similarity $((V s 1),(V s 2))$.

3. After deriving the similarity score between user's question and every question in the dataset, select the question's prioritized answers ranked by similarity scores to provide the best answers from the dataset. The same method is used to retrieve contents from international standard files. The system compares the similarity between the titles or sub-titles of files and user questions to provide users with the most relevant content related to international standards.

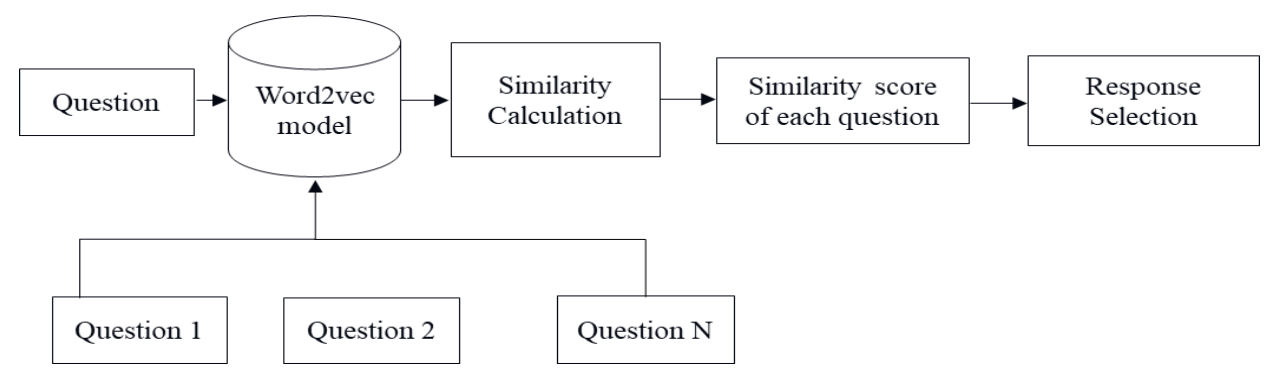

Figure 7. FAQ dataset used for similarity calculation. 


\subsection{Cost Estimation System}

Power transformers are critical equipment for power plants and substations that are highly customized to satisfy customer needs. Manufacturers and customers must have honest and trusted communications when negotiating prices. By introducing the cost estimation sub-system, customers have a preliminary understanding of the price of the product. An RFQ in the power transformer industry is a document used to request bids from qualified manufactures of transformers. The RFQ document specifies the requirements of the transformer to be purchased.

The first task for constructing a cost estimation system is to build a knowledge base (KB). The knowledge base contains the estimated cost of all key materials or components for transformers. The cost data of a given RFQ are retrieved from the KB and put into the $\mathrm{BOM}$ table for instant cost aggregation. The information of the prototype knowledge base is built using a MySQL database management server [57]. The MySQL server independent from the cost estimation program. Accessing the database through SQL makes the back-end database easier to update or replaced with existing ERP cost modules. The proposed VR consultation system uses the information stored in the MySQL server such that data are passed to the Unity environment. The Chatbot shows the cost estimation results by tagging the transformer and its components' 3D VR modals. The BOM generation enables the customer to receive a tentative cost estimation of the transformer design when sending an RFQ to the manufacturer. These quotes are critical factors that determine product costs that enable manufacturers and customers greater flexibility in negotiations.

\subsection{Virtual Reality Environment}

The 3D transformer models can be accessed either by computer or in immersive way with HTC VIVE helmet and controller. The following sections introduce the modeling software used in this research and the development of Unity 3D game engine applications.

SolidWorks, the first Windows-based 3D CAD modeling software, is used in engineering design and provides a powerful platform for the design of components. SolidWorks simplifies assembly design and provides the same visualization as in the real-world, designand-obtain functions, and allows users to view, rotate, and even enter the interior of the equipment. Unity 3D is used to construct the user interaction environment. Unity is a cross-platform game engine that enables users to create games, simulations and interactive experiences in both $2 \mathrm{D}$ and $3 \mathrm{D}$, and the engine offers a primary scripting API in C\#. The development environment of Unity is divided into scene design interface, scene object structure, object structure, object list, object attribute, and execution interface. When designing the user interface of the Unity program in this research, there are three parts: the chatbot (dialogue window), model interaction area, and the functions list.

1. Chatbot (Dialogue window): Users can interact with the chatbot system within a dialogue window to conduct an engineering consultation via a keyboard or microphone.

2. Model interaction: Users interact with 3D models in real time, and can choose key components (i.e., conservator, bushing, cooling system) to view relevant specification information in the VR environment. The specified commands to disassemble the model are used to spread out the internal core structure.

3. Functions list: Users may customize the components or specifications of models, such as replacing some components or toggle from indoor scene to outdoor scene.

\subsection{Systems Integration}

The previous sections discuss the methods and processes for constructing the three sub-systems. This section discusses how to integrate the question answer chatbot with the cost estimation system in a VR environment. The first subsystem includes a preprocessing module, a word embedding model, and a similarity calculation module. Python code is used for NLP and to build the chatbot. Python provides a rich natural language toolkit library to help with data pre-processing and word vector model training. The Chatbot can covert a user's question into a vector and retrieve the best answers from FAQ dataset or files 
from the knowledgebase. Figure 8 shows the synergy of proposed integrated chatbot. When the user enters a question, the Q\&A engine retrieves possible answers and sends a response to the user. Since the chatbot is integrated with VR module, the relevant components or specification information about the power transformer is displayed on the VR model. As for the cost estimation module, the BOM of components are retrieved and the costs are estimated. The model interactions described in Section 3.3 are also illustrated in Figure 8, including model disassembly, indoor/outdoor scene change, and customization.

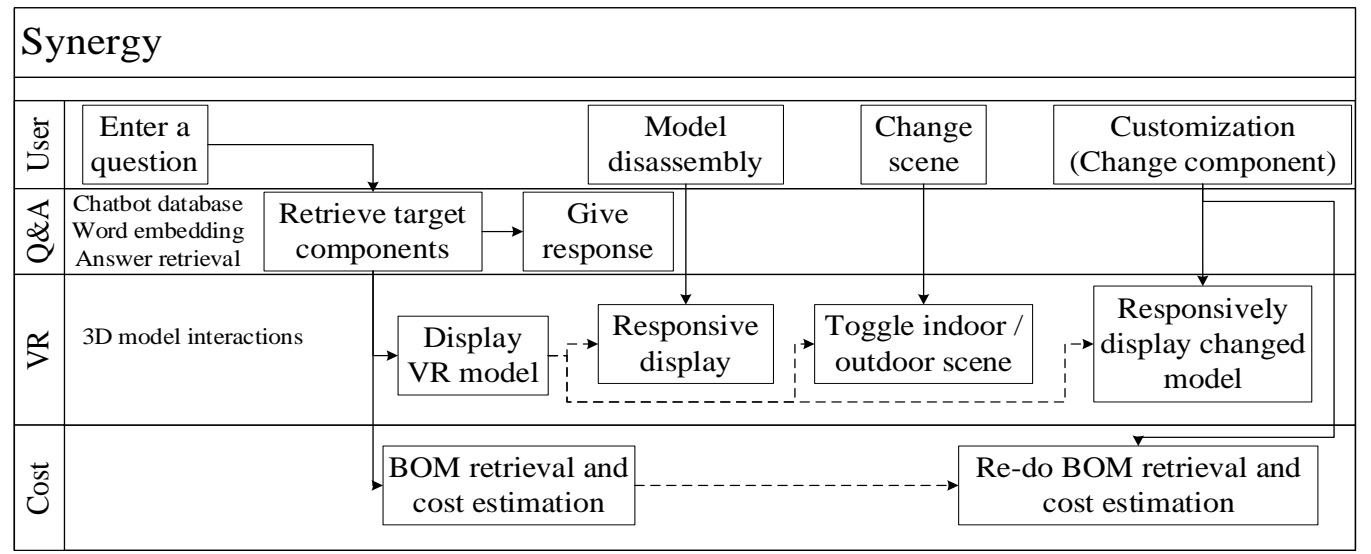

Figure 8. Synergy of the proposed integrated chatbot system.

By integrating chatbot with VR and the cost estimation module, the system helps customers understand the product more comprehensively, and provides the advantages of providing real-time interaction of text and 3D models for collaborative engineering design and customer sales.

In the second sub-system, given the large number of components and materials used to build a power transformer, a relational database is used to store information in the knowledge base. The information of the knowledge base uses the MySQL database server. The information includes raw materials, specifications, and the unit cost of key components stored in the MySQL server. The data are passed back to the Unity environment of the Chatbot to generate a BOM table of the estimated cost using a Net Framework. Figure 9 shows the proposed system connects the three sub-systems by the user interface, which is developed in Unity 3D and controlled by C\# programming language.

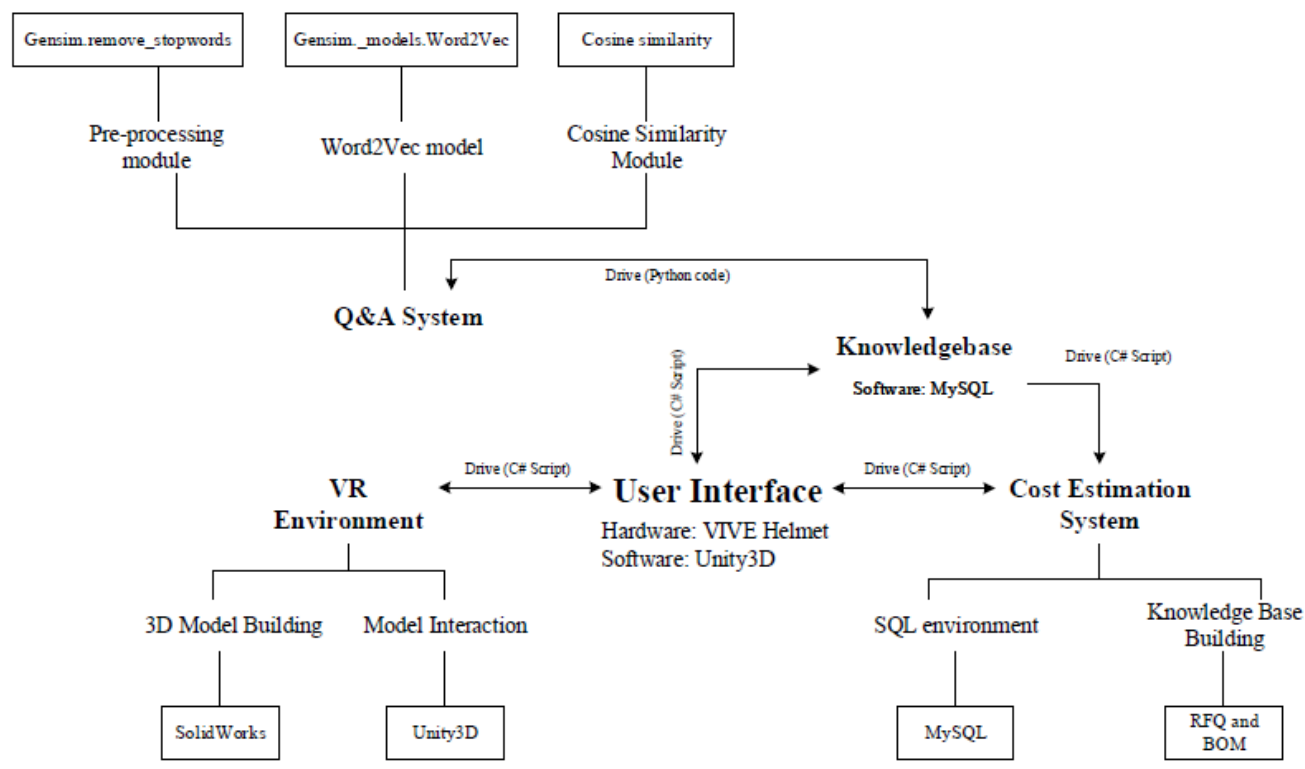

Figure 9. Hardware and software integration of the proposed chatbot system. 


\section{Case Implementation, Verification, and Demonstration}

The system provides real-time engineering consultation, an automatically generated BOM for cost estimation when receiving an RFQ summary file and provides user an immersive environment to interact with 3D models. This section discusses the implementation of the system including the introduction of functions, interface design, and verification of the consultation Q\&A accuracy. The case demonstration focuses on the VR-enabled consultation Chatbot functions supporting transformer mass-customization.

\subsection{Chatbot Implementation and Verification}

The consultation Chatbot implementation shows that users can easily ask questions in English and receive a concise and insightful answer in real-time. The question-and-answer dataset used in this system comes from the public FAQs on the webpages of different power transformer suppliers. The answering capability of consultation Chatbot depends on the completeness and correctness of the FAQ database. Therefore, the collection of accurate data for the FAQ database is essential and must be evaluated by a domain expert. Our data were verified by an engineer from a large power transformer company. The questions include transformer engineering knowledge and customer support consultation. Table 3 provides examples of the FAQ database.

The functions of the proposed Chatbot can be organized by three parts: answering users' questions within the FAQs database, linking external databases to improve the accuracy of answers within the domain, and constructing an error reporting function to dynamically update and modify the database. One hundred questions are used to evaluate the accuracy rate of the proposed chatbot. The questions are collected from Quora (www.quora.com, accessed on 24 January 2021). Adopting the concept of collective intelligence, all the questions and answers in Quora are created, edited, and organized by the engineers who will use the system. The source of the database used in this research is the FAQs collected from power transformer manufacturers, and the test questions are used to verify whether the Chatbot can answer frequently asked questions related to transformers, e.g., the relevant technologies, product specifications and service provision by manufacturers. The testing result shows that more than $85 \%$ of 150 transformer questions, randomly selected from Quora, are answered correctly by the proposed system when compared to the Quora collective answers. This system demonstrates its general knowledge capability for answering the public's questions related to transformers. Quora's answers are sometimes incorrect since the source is from the collective intelligence of the general public who may or may not have sufficient transformer knowledge. As for the answers in the proposed system, the Q\&A dataset is sourced directly from transformer manufacturers, who are experts in the power transformer knowledge domain. The verification process of engineering consultation Chatbot performance shows that industry specific Chatbots rely on a large amount of professional knowledge to provide correct and adequate answering services. Testing data from different sources helps identify the shortcomings of the Chatbot system's Q\&A interpretation and its FAQ dataset for modification and improvement.

During engineering consultation, international customers are often concerned about compliances with international and national standards such as IEEE, IEC, and ANSI regarding transformer design and installations. Using the database established previously, in addition to being able to retrieve answers from the FAQs dataset, the chatbot provide users with content relevant to international standard documents. Table 4 shows an example of questions and answers about international standards and the similarity between user's question and the titles or sub-titles in international standard files. As seen with question 1 in the table, users can search with keywords for specific standard document chapters. The system will provide the relevant content response, and question 2 shows that if the user enters keywords without a specific standard, the system will perform an entire database search and return the relevant contents with locations of the files and chapters from the specific standards and regulations. 
Table 3. The sample FAQs for Chatbot Q\&A.

\begin{tabular}{|c|c|c|}
\hline Type & Question & Answer \\
\hline \multirow[t]{4}{*}{ 1. Transformer } & $\begin{array}{l}\text { What is the material of the } \\
\text { transformer core? }\end{array}$ & $\begin{array}{l}\text { A transformer core is made from } \\
\text { many sheets of special steel to ... }\end{array}$ \\
\hline & $\begin{array}{l}\text { What are the losses in a } \\
\text { transformer? }\end{array}$ & $\begin{array}{l}\text { In any electrical machine, "loss" } \\
\text { can be defined as the difference } \\
\text { between ... }\end{array}$ \\
\hline & $\begin{array}{l}\text { Can transformers be used in } \\
\text { parallel? }\end{array}$ & $\begin{array}{l}\text { Single phase transformers can be } \\
\text { used in parallel only when their } \\
\text { voltages are equal ... }\end{array}$ \\
\hline & $\begin{array}{l}\text { What is a temperature rise test } \\
\text { for a transformer? }\end{array}$ & $\begin{array}{l}\text { Temperature rise tests are an } \\
\text { optional test and are usually not } \\
\text { performed ... }\end{array}$ \\
\hline \multirow[t]{4}{*}{ 2. International Standard } & $\begin{array}{l}\text { What is the international } \\
\text { standard we should choose? }\end{array}$ & $\begin{array}{l}\text { In accordance with the IEEE } \\
\text { standard design will be the most } \\
\text { economical ... }\end{array}$ \\
\hline & $\begin{array}{l}\text { What role does the } \\
\text { government play in ANSI's } \\
\text { activities? }\end{array}$ & $\begin{array}{l}\text { Since the time agencies of the } \\
\text { federal government joined ... }\end{array}$ \\
\hline & $\begin{array}{l}\text { What are the benefits of ISO } \\
9001 \text { certification? }\end{array}$ & $\begin{array}{l}\text { Enhanced Customer Satisfaction. } \\
\text { Increased productivity, efficiency } \\
\text { and profit ... }\end{array}$ \\
\hline & $\begin{array}{l}\text { Does ANSI develop the U.S. } \\
\text { position on ISO and IEC } \\
\text { standards? }\end{array}$ & $\begin{array}{l}\text { Yes and No. ANSI and its U.S. } \\
\text { National Committee for the IEC } \\
\text { (USNC) help ... }\end{array}$ \\
\hline \multirow[t]{4}{*}{ 3. Customer Service } & $\begin{array}{l}\text { How long does installation } \\
\text { take? }\end{array}$ & $\begin{array}{l}\text { Installation usually requires six to } \\
\text { eight weeks. }\end{array}$ \\
\hline & $\begin{array}{l}\text { Is there a local service team in } \\
\text { the US? }\end{array}$ & $\begin{array}{l}\text { The US has two service centers. } \\
\text { One on the West coast in } \\
\text { California, and one on the east } \\
\text { coast in Pennsylvania. }\end{array}$ \\
\hline & $\begin{array}{l}\text { What is the source of silicon } \\
\text { steel material in transformers? }\end{array}$ & $\begin{array}{l}\text { (1) Japan (2) Korea (3) United } \\
\text { States (4) China }\end{array}$ \\
\hline & $\begin{array}{l}\text { Do you provide GIC } \\
\text { computing? }\end{array}$ & $\begin{array}{l}\text { Yes, we also provide outsourcing } \\
\text { for computing certification. }\end{array}$ \\
\hline \multirow[t]{4}{*}{ 4. Engineering Knowledge } & What is induced electricity? & $\begin{array}{l}\text { Electricity generated by relative } \\
\text { motion of a magnetic field and an } \\
\text { electric charge. }\end{array}$ \\
\hline & $\begin{array}{l}\text { How do you get rid of static } \\
\text { electricity? }\end{array}$ & $\begin{array}{l}\text { If you've built up static charge on } \\
\text { yourself and want to get rid of it, } \\
\text { then you need ... }\end{array}$ \\
\hline & $\begin{array}{l}\text { What is the power factor in } \\
\text { AC circuits? }\end{array}$ & $\begin{array}{l}\text { The power factor of an } \mathrm{AC} \text { electric } \\
\text { power system is defined as the } \\
\text { ratio of the real ... }\end{array}$ \\
\hline & Who discovered electricity? & $\begin{array}{l}\text { Benjamin Franklin, but a lot of } \\
\text { scientists contributed in the } \\
\text { discovery ... }\end{array}$ \\
\hline
\end{tabular}


Table 4. Examples of questions and answers related to international standards.

\begin{tabular}{|c|c|c|c|}
\hline \# & Question & Answers & Similarity \\
\hline \multirow{3}{*}{1} & \multirow{3}{*}{$\begin{array}{l}\text { Tell me IEEE standard } \\
\text { about bushings }\end{array}$} & $\begin{array}{l}\text { In IEEE - C57.12.10: Bushings: The } \\
\text { insulation level of line bushings shall be } \\
\text { equal to or greater than the insulation level } \\
\text { of the windings to which they are connected. } \\
\text { The insulation level of the low-voltage } \\
\text { neutral ... }\end{array}$ & $93 \%$ \\
\hline & & $\begin{array}{l}\text { In IEEE-C57.12.00: Bushings: Transformers } \\
\text { shall be equipped with bushings with an } \\
\text { insulation level no less than that of the } \\
\text { winding terminal to which they are } \\
\text { connected, unless otherwise specified... }\end{array}$ & $93 \%$ \\
\hline & & $\begin{array}{l}\text { In IEEE C57.19.00: Open bushing: A } \\
\text { bushing the internal parts of which are } \\
\text { exposed to the interior of the apparatus in } \\
\text { which it is mounted ... }\end{array}$ & $73 \%$ \\
\hline \multirow{3}{*}{2} & \multirow{3}{*}{$\begin{array}{l}\text { Are there any } \\
\text { standards about wire } \\
\text { size? }\end{array}$} & $\begin{array}{l}\text { In NEMA - ICS6: Minimum Screen Wire } \\
\text { Size: Where openings are screened, the wire } \\
\text { gauge of the screen shall be not less than No. } \\
16 \text { AWG ... }\end{array}$ & $64 \%$ \\
\hline & & $\begin{array}{l}\text { In NEMA - ICS6: WIRE BENDING SPACE: } \\
\text { Enclosures shall be constructed such that, } \\
\text { after the apparatus has been mounted } \\
\text { within the enclosure ... }\end{array}$ & $50 \%$ \\
\hline & & $\begin{array}{l}\text { In ASME B16.5: } 3.1 \text { Nominal Pipe Size: As } \\
\text { applied in this Standard, the use of the } \\
\text { phrase "nominal pipe size" or the } \\
\text { designation NPS followed by a } \\
\text { dimensionless number is for the purpose ... }\end{array}$ & $36 \%$ \\
\hline
\end{tabular}

Table 5 shows several questions and answers from the 150 questions in test dataset. The testing questions are used to verify the chatbot system can answer frequently asked questions related to transformer technologies in depth when comparing to Quora answers.

Some Q\&A Chatbots (mostly focusing on less complex domains) and the proposed Q\&A Chatbot are compared to verify the advances of the proposed system (see Table 6). Lelis, et al. [58] proposed Nadine-Bot, which is an open domain migrant integration administrative agent for answering questions related to immigration to the European Union. Nadine-Bot retrieves multiple documents in the database and responses. Each document has a title and text with related content. A two-step process is used in the system. The first step is to find the largest number of matching documents by comparing the Cosine similarity of the question and the document. Then, the second step is to find paragraphs in the document that meet the intent of the question. The system is fine-tuned with Simple BERT. Although the adjusted accuracy is better than the original method, it is only about $42 \%$ accurate. Bao, et al. [59] proposed $\mathrm{HHH}$, an online medical Chatbot system based on knowledge graph and hierarchical bi-directional attention, to provide complex medical question and answer functions. By combining the knowledge graph constructed from the information collected on the Internet and the text similarity model using the Hierarchical BiLSTM Attention Model (HBAM), the most similar questions are retrieved from a large Q\&A data set according to the user's question and adopted into the corresponding answer. Three websites, ehealthforumQAs, questionDoctorQAs and webmdQAs, are used to evaluate the system and their accuracy rates are all $81 \%$. Carlander-Reuterfelt, et al. [60] proposed a Chatbot applied to teaching that is divided into two different dialogue modes, i.e., chat and Q\&A. A FAQ database was built by collecting frequently asked questions and their answers in the non-engineering and non-technical teaching domain. During Q\&A, answers 
were found in the database using a keyword search. The study conducted a systematic evaluation and the answer accuracy was 85\%. Mondal, et al. [61] also proposed a Chatbot for Q\&A for the non-technical education field. The system collected 1500 Q\&A sets, carried out data pre-processing by turning them into structured data, and finally produced about 1000 structured Q\&A sets. The language model used is Bag-of-words, and feature extraction forms the basis for selecting answers. Although the system used a web crawler to enhance the database to reach an accuracy rate of $89 \%$, the knowledge domain does not include the engineering domain. Compared with an accuracy rate of $85 \%$ for the Chatbot in this research, it is believed that the slightly lower accuracy rate is due to the complexity of the engineering knowledge acquisition and organization and the difficulty of building a comprehensive engineering Q\&A database.

Table 5. Examples of Quora test questions.

\begin{tabular}{|c|c|c|c|}
\hline$\#$ & Question & Answer (Quora) & Answer (Proposed Chatbot) \\
\hline 9 & $\begin{array}{l}\text { What is Condition } \\
\text { Monitoring test on } \\
\text { transformer? }\end{array}$ & $\begin{array}{l}\text { Condition monitoring } \\
\text { tests are used to assess } \\
\text { the health of an ... }\end{array}$ & $\begin{array}{l}\text { Online condition monitoring is a } \\
\text { type of monitoring system in } \\
\text { which the data are sent online ... }\end{array}$ \\
\hline 10 & $\begin{array}{l}\text { What is the difference } \\
\text { between power } \\
\text { transformer and rectifier } \\
\text { transformer? }\end{array}$ & $\begin{array}{l}\text { So far as transformer } \\
\text { alone is considered, no } \\
\text { difference... }\end{array}$ & $\begin{array}{l}\text { A 'power transformer' is simply } \\
\text { a category of transformer type } \\
\text {.. }\end{array}$ \\
\hline 55 & What are the stray losses? & $\begin{array}{l}\text { Stray loss is one of the } \\
\text { losses that occur in an } \\
\text { electrical machine. }\end{array}$ & $\begin{array}{l}\text { Stray losses result from the eddy } \\
\text { currents set up by the leakage } \\
\text { flux... }\end{array}$ \\
\hline 59 & $\begin{array}{l}\text { Why NGR is connected in } \\
\text { LV side of transformer? }\end{array}$ & $\begin{array}{l}\text { NGR has } 2 \text { functions to } \\
\text { the power system such as: } \\
1 \text { / Correct effectively } \\
\text { grounded ... }\end{array}$ & $\begin{array}{l}\text { The fundamental purpose of a } \\
\text { Neutral Grounding Resistor } \\
\text { (NGR) is to limit ground fault ... }\end{array}$ \\
\hline 71 & $\begin{array}{l}\text { Is transformer oil } \\
\text { flammable? }\end{array}$ & $\begin{array}{l}\text { Yes, it is a type of mineral } \\
\text { oil so it is flammable. Its } \\
\text { flash point is } 140 \text { degrees } \\
\text { Celsius. }\end{array}$ & $\begin{array}{l}\text { It is a type of mineral oil so it is } \\
\text { flammable. Its flash point is } 140 \\
\text { degrees Celsius. }\end{array}$ \\
\hline 78 & $\begin{array}{l}\text { How do I test } \\
\text { transformer windings? }\end{array}$ & $\begin{array}{l}\text { Consider a simple } \\
\text { situation: you have an } \\
\text { unknown transformer in } \\
\text { your junk box and ... }\end{array}$ & $\begin{array}{l}\text { The transformer winding } \\
\text { resistances can be measured by } \\
\text { current voltage method ... }\end{array}$ \\
\hline 119 & $\begin{array}{l}\text { What is the permissible } \\
\text { maximum flux density in } \\
\text { transformer core? }\end{array}$ & $\begin{array}{l}1.6 \text { to } 1.8 \text { weber per } \\
\text { meter. }\end{array}$ & $\begin{array}{l}\text { The maximum value of the } \\
\text { magnetic flux density is } 1.1 \mathrm{~T} \\
\text { when } 2200 \text { volts, } 50 \mathrm{~Hz} \text { is applied } \\
\text { to the transformer primary } \\
\text { winding. }\end{array}$ \\
\hline 144 & $\begin{array}{l}\text { How is the winding } \\
\text { named according to the } \\
\text { voltage? }\end{array}$ & $\begin{array}{l}\text { High voltage winding } \\
\text { and Low voltage } \\
\text { winding. }\end{array}$ & $\begin{array}{l}\text { These terms are used to } \\
\text { distinguish the winding having } \\
\text { the greater voltage rating from } \\
\text { that having the lesser in two } \\
\text { winding transformers. }\end{array}$ \\
\hline \multicolumn{3}{|c|}{ Chatbot accuracy (of 150 tested QAs): } & $84.9 \%$ \\
\hline
\end{tabular}


Table 6. Comparison of the proposed system with other Q\&A Chatbots.

\begin{tabular}{|c|c|c|c|c|}
\hline & $\begin{array}{l}\text { Knowledge } \\
\text { Base }\end{array}$ & $\begin{array}{l}\text { Answer } \\
\text { Selection }\end{array}$ & Language Model & Accuracy \\
\hline This research & $\begin{array}{l}\text { Closed domain } \\
\text { with Q\&A pairs }\end{array}$ & Cosine similarity & $\begin{array}{l}\text { Word2Vec, } \\
\text { skip-gram }\end{array}$ & $85 \%$ \\
\hline $\begin{array}{l}\text { Lelis, Vretos and } \\
\text { Daras [58] }\end{array}$ & $\begin{array}{l}\text { Documents with } \\
\text { specific content }\end{array}$ & Cosine similarity & $\begin{array}{l}\text { Modified simple } \\
\text { BERT }\end{array}$ & $39-42 \%$ \\
\hline Bao, Ni and Liu [59] & $\begin{array}{l}\text { Open domain, } \\
\text { Q\&A pairs, } \\
\text { knowledge } \\
\text { graph }\end{array}$ & $\begin{array}{l}\text { semantic } \\
\text { similarity } \\
\text { calculation }\end{array}$ & $\begin{array}{l}\text { knowledge graph, } \\
\text { Hierarchical } \\
\text { Bi-LSTM Attention } \\
\text { Model }\end{array}$ & $81 \%$ \\
\hline $\begin{array}{l}\text { Carlander- } \\
\text { Reuterfelt, Carrera, } \\
\text { Iglesias, Araque, } \\
\text { Rada and } \\
\text { Muñoz [60] }\end{array}$ & $\begin{array}{l}\text { Open domain, } \\
\text { Q\&A pairs }\end{array}$ & $\begin{array}{l}\text { key terms } \\
\text { similarity }\end{array}$ & $\begin{array}{l}\text { SVC (Support Vector } \\
\text { Classifier) }\end{array}$ & $85 \%$ \\
\hline $\begin{array}{l}\text { Mondal, Dey, Das, } \\
\text { Nagpal and } \\
\text { Garda [61] }\end{array}$ & $\begin{array}{l}\text { Open domain, } \\
\text { Q\&A pairs }\end{array}$ & $\begin{array}{l}\text { Random forest } \\
\text { used for } \\
\text { classifying }\end{array}$ & Bag-of-words & $89 \%$ \\
\hline
\end{tabular}

Compared with these studies, the Chatbot in this study uses a relatively simple skipgram word2vec structure with cosine similarity approach and provides acceptable results, which is due to the choice of appropriate knowledge bases and models. The knowledge base of this study is composed of a large number of QA pairs, and retrieval-based method has been proven to be suitable for use in chatbots with QA pairs as the corpus [62], which is just like looking up data using a dictionary index. This research uses international standards, noun dictionaries, and FAQ data sets as the source of the knowledge base, which can be intuitively expressed in the form of QA pairs to increase performance of the general approach. The Chatbot structure can be further improved by adopting more sophisticated NLP neural modelling algorithms. Nonetheless, the main objective of this research is to demonstrate intelligent chatbots with VR HCI for highly customized machinery design and manufacturing consultation including request for quotations. The $85 \%$ accuracy rate obtained with the lightweight structure demonstrates the efficiency and effectiveness of the Chatbot used in this research.

Although recent research on the integration of Chatbots into VR is insufficient, there are comparable research studies. The comparison contains three key capabilities, including whether it is an NLP-based HCI, whether it is an immersive VR, and whether it is capable of Q\&As using engineering domain knowledge. Three recent Chatbot systems are listed for the comparison. Wickramasinghe, et al. [63] proposed a 3-D virtual environment for interior design, which allows users to add 3-D furniture models using natural language or gestures. Malik, et al. [64] proposed a unified framework that combines human-machine simulation and VR to evaluate work details and make decisions. Stanica, et al. [65] proposed VR Job, a simulated interview system that combines VR and NLP. Table 7 shows the highlights of the comparison with respect to their capabilities in NLP, VR immersion, and Q\&A with engineering knowledge. The Amazon Sumerian is an authoring tool to create VR and immersive applications, with which a chatbot application can be combined by Amazon Lex. Furthermore, other tools in the Amazon ecosystem can provide a richer user experience. For example, Amazon Polly can provide text and voice conversion, and Sumerian Host provides a dialogue management mechanism. Currently known applications are Electronic Caregiver (ECG), which is an AI-driven 3D Web virtual care platform, and Fidelity Labs, a hosted VR experience with data visualization. 
Table 7. The key capabilities of intelligent Chatbot research.

\begin{tabular}{|c|c|c|c|c|}
\hline & $\begin{array}{l}\text { NLP Capabil- } \\
\text { ity/Tools }\end{array}$ & $\begin{array}{l}\text { VR Immer- } \\
\text { sion/Tools }\end{array}$ & $\begin{array}{l}\text { Engineering } \\
\text { Knowledge }\end{array}$ & Applications \\
\hline This research & Yes/Gensim & Yes/HTC Vive & $\begin{array}{l}\text { Power } \\
\text { transformer }\end{array}$ & $\begin{array}{l}\text { Engineering } \\
\text { consultation }\end{array}$ \\
\hline $\begin{array}{l}\text { Wickramasinghe, } \\
\text { De Saram, } \\
\text { Liyanage, } \\
\text { Rangika and } \\
\text { Ranathunga [63] }\end{array}$ & $\begin{array}{l}\text { Yes / Apache } \\
\text { OpenNLP }\end{array}$ & No/OpenCV & No & $\begin{array}{l}\text { Classroom/teaching } \\
\text { supports }\end{array}$ \\
\hline $\begin{array}{l}\text { Malik, Masood } \\
\text { and Bilberg [64] }\end{array}$ & No & $\begin{array}{l}\text { Yes/Siemens NX } \\
\text { HTC Vive }\end{array}$ & $\begin{array}{l}\text { Bill of } \\
\text { process } \\
(\mathrm{BOP})\end{array}$ & $\begin{array}{l}\text { Digital twin and } \\
\text { human robot } \\
\text { collaboration (HRC) }\end{array}$ \\
\hline $\begin{array}{l}\text { Stanica, Dascalu, } \\
\text { Bodea and } \\
\text { Moldoveanu } \\
\text { [65] }\end{array}$ & No/AIML & Yes/HTC Vive & No & Job interviews \\
\hline $\begin{array}{l}\text { Amazon } \\
\text { Sumerian }\end{array}$ & $\begin{array}{l}\text { Yes/Amazon } \\
\text { Lex }\end{array}$ & $\begin{array}{l}\text { Yes/Amazon } \\
\text { Sumerian }\end{array}$ & $\begin{array}{l}\text { Customer } \\
\text { services }\end{array}$ & $\begin{array}{l}\text { Customer service } \\
\text { data visualization }\end{array}$ \\
\hline
\end{tabular}

\subsection{VR-Enabled Consultation Chatbot Demonstration}

This section introduces the implementation of the VR-enabled consultation chatbot. Users interact with 3D models using a keyboard or mouse without the VR hardware. The VR setting enables users to interact with the system wearing a helmet and controller in the immersive environment. For the prototype, a typical power transformer has main components such as windings, core, bushings, conservator, transformer oil, tap changer, and a breather. The 3D models of the external and internal components are constructed using accurately scaled sizes. Figure 10 shows the four models constructed in this research. After the construction is completed, the models are put into the Unity development environment for interactive design and C\# script writing.
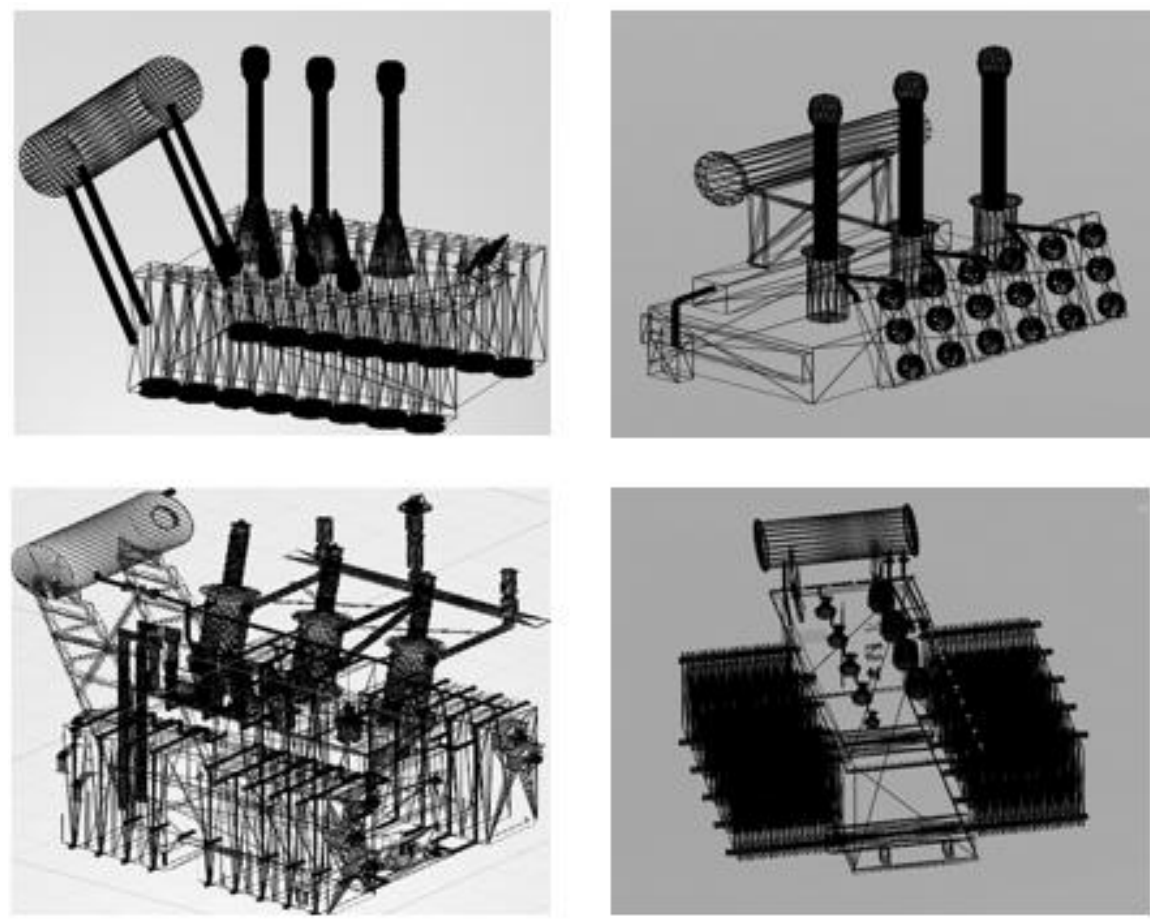

Figure 10. Four power transformers constructed in this research. 
Customers require that transformer manufacturers be installed in different working environments, including indoor or outdoor environments. As shown in Figure 11, the outdoor environment simulates a transformer installed in a desert. The critical issues for installation such as "how to lay and attach the electric wire" and "how to determine the precise position of the transformer," must be considered during the transformer design. The VR chatbot can help the manufacturer and customer increase the efficiency of the design process. Another scene simulates a large transformer set inside a building, which must consider space, vibration, heat, and noise constraints. The VR-enabled system helps both customers and manufacturers during transformer design, manufacturing, installation, repair, maintenance, and disposal stages.
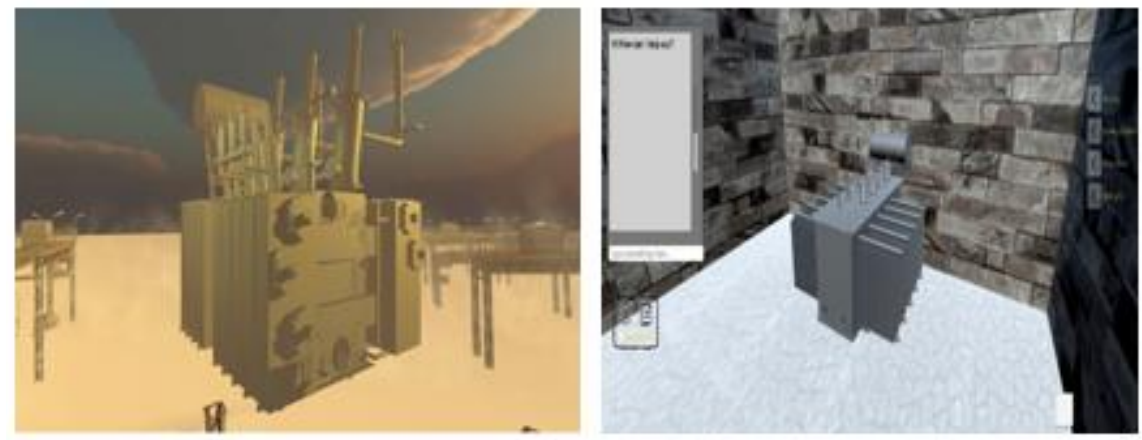

Figure 11. The outdoor and indoor transformer scenes.

Figure 12 shows the interfaces of consultation system. The first part on the top-left corner is a chatbot window, where users can easily enter text and ask the system to answer questions for engineering consultation. Voice recognition and language translation functions can be switched on/off in the chatbot interface. The lower left box contains the buttons that enable immersive interactions between the users and the object models for assembly/disassembly and transparent views for internal inspections. The third part enables users with a choice of replacement parts. As previously discussed, power transformers are highly customized industry equipment. Different customers have different needs for products and outsourced components. Using this function, customers can change components and the model and other information while the BOM table will be updated in real time to show how changes are affecting the product configuration and the cost of the final product.

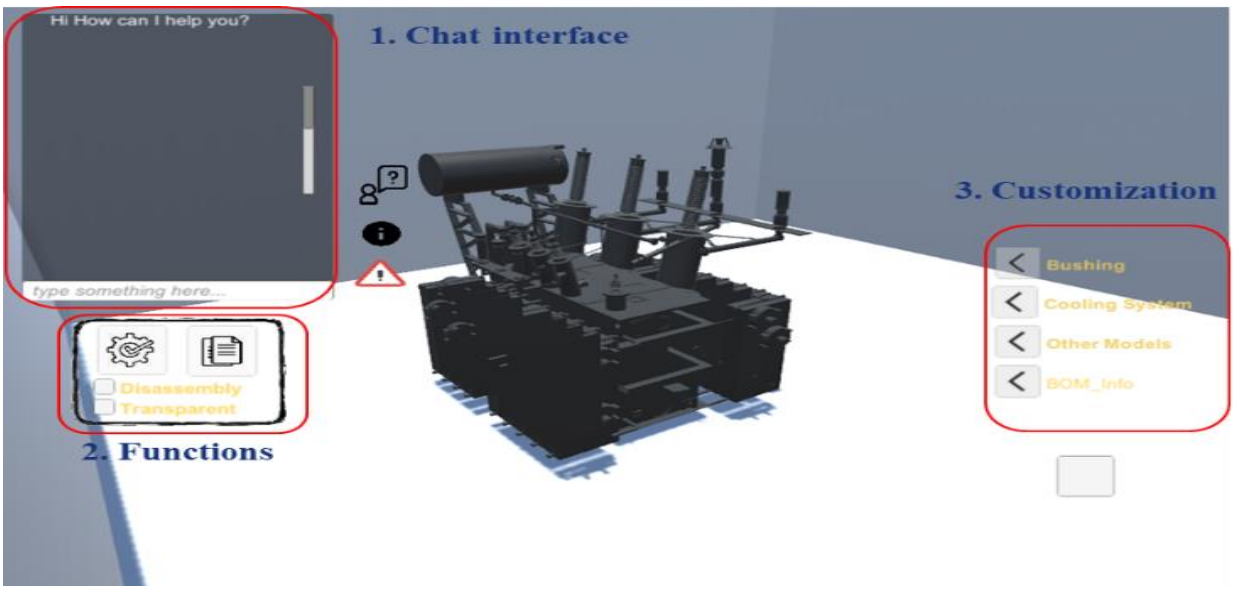

Figure 12. Interfaces of the consultation chatbot system.

The chatbots strategically helps companies respond to customers immediately, automatically, and without time barriers providing a strategic advantage. The environment 
provides a good customer experience with an immediate response that increases service satisfaction and can be used concurrently with a sales engineer. Virtual reality provides users with an experience that better helps them understand the appearance and functions of the product. This system integrates the advantages of chatbots and VR technologies, enables users to receive textual responses and provide model interaction in real time. In addition to answering user questions, the question answering system sends commands to make the model interaction events relate to the user's question activities. Table 8 demonstrates Q\&As and their related user interactions in the VR environment. Question 1 "What are the key component of a transformer?" The proposed VR Chatbot provides users with the details of key components of a power transformer. In addition, as shown in Figure 13, the system presents the animation for transformer disassembly. By disassembling the transformer, the user can better understand the details of components and structure. Users can also activate events by clicking the button or saying a specific word. For example, the user can say "disassemble" to the system. Within two seconds, when the speech recognition system receives this command, it will generate the model disassembly animation.

Table 8. Demonstrations of Q\&As and VR interactions in VR Chatbot.

\begin{tabular}{|c|c|c|}
\hline \# & Question & Answer \\
\hline 1 & $\begin{array}{c}\text { What are the key components } \\
\text { of a transformer? }\end{array}$ & $\begin{array}{l}\text { There are three basic parts if a transformer: } \\
\text { an iron core that serves as a magnetic } \\
\text { conductor, a primary winding or coil of wire } \\
\text { and a secondary winding... }\end{array}$ \\
\hline 2 & $\begin{array}{l}\text { What are the types of } \\
\text { transformer cores? }\end{array}$ & $\begin{array}{l}\text { Mainly there are two types: Core type. Shell } \\
\text { type. Windings are the conductors wrapped } \\
\text { in various forms like helical, disc, cylindrical, } \\
\text { crossover that generates ... }\end{array}$ \\
\hline 3 & $\begin{array}{l}\text { Why should bushings be } \\
\text { installed on the transformer? }\end{array}$ & $\begin{array}{l}\text { A bushing is an insulated device that allows } \\
\text { an electrical conductor to pass safely through } \\
\text { a grounded conducting barrier such as the } \\
\text { case of a transformer... }\end{array}$ \\
\hline
\end{tabular}

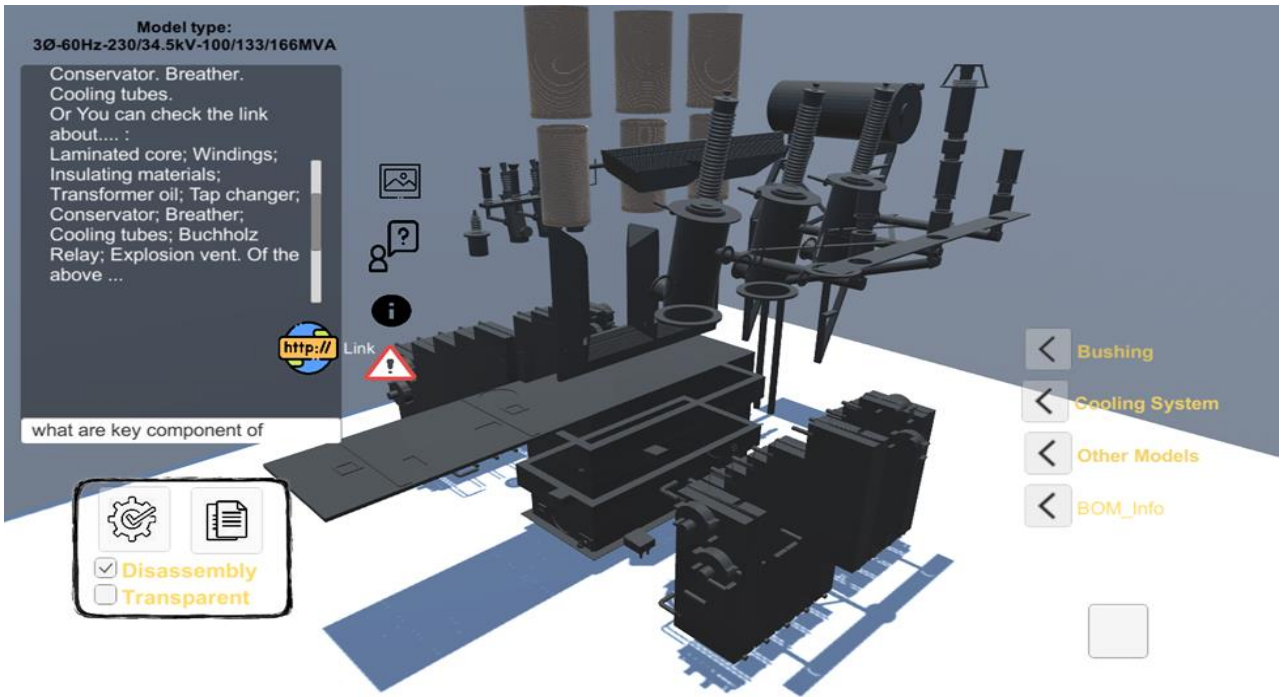

Figure 13. VR immersive interface with chatbot dialog window.

The VR chatbot can also activate model events related to questions. For example, when the customer asks, "What are the types of transformer cores?", the Chatbot provides information about transformer cores and activates another function, transformer hyalinization at the same time using the relational knowledge base. In the dialog window, the system 
provides the answer about introduction of transformer cores: "Mainly there are two types: Core-Type and Shell-Type...". At the same time, the material of the 3D transformer model becomes transparent such that users can directly see the core of the presented product in the VR environment and additional core types and specifications can be seen on the right-hand side. The transparency of the transformer will gradually increase, and users can see the detail of coil and inner structure.

The VR system provides real-time replacement of transformer components such as bushings or cooling systems, and users can also select other transformer models to see what other in-use transformer configurations resemble. Referring to Question 3, when the users ask about a specific component of a power transformer, the system displays the component and can exchange it. The transformer BOM (assembly structure) can be expanded, which enables users to change options of components and display the installed position. The functions in the VR environment can switch the components, view the overall model, list design specifications and the cost estimations when changed.

\section{Conclusions}

This research proposes a system framework for a VR-enabled engineering consultation chatbot. In addition to providing engineering consultation, the system also combines the advantages of VR to provide a user with immersive three-dimensional interfaces, which help improve understanding of complex power transformer designs and manufacturing. The contributions of this study are listed as follows:

1. A VR-enabled chatbot integrates power transformer knowledge base, Q\&A natural language processing, and cost estimation modules, that users can interact with in an immersive environment. This allows users to ask technical questions, receiving accurate answers, obtaining tentative costs, while interacting with 3D models for vivid design reviews (necessary for mass customization of complex products). The performance of the proposed chatbot system is verified in comparison to related studies.

2. The performance of the proposed chatbot system is verified in comparison to some related studies and literature.

3. This research proposes an enhanced chatbot application context. By combining the cost estimation module, chatbot can integrate with the enterprise information system database to provide better design or manufacturing services, not just a tool.

For theoretical implications, the convergence of chatbot and VR is promising. Achieving hybrid automation in manufacturing through VR has received ample attention [64], but most application people are limited to the two dimensions of communication between "people" and "environment". In this study, the smart agent, Chatbot, was placed into the interactive VR prototype to provide 24/7 intelligent engineering consulting services, bringing the additional third dimension to the application of VR. For managerial implications, it is worth further study to combine chatbot technologies with the existing enterprise information systems to improve manufacturing service efficiency and improve user experiences.

There are some limitations of this research. The design and development of an enterprise information system is time-consuming, including the design of the user interface, the domain knowledge framework construction, and the establishment of the knowledge base. This research uses a QA-based knowledge base; thus, the engineering consultant chatbot can be implemented using a lightweight framework without degrading performance. However, if the knowledge base of chatbot and the enterprise management information system are integrated such that the chatbot can answer more comprehensive questions as a comprehensive smart agent, this will require a huge amount of work. In terms of VR, all interactive scenarios must be explored and designed, which rely on detailed design of objects in the VR environment. To provide an experience comparable to the actual environment, huge costs are needed to develop a system that is not a game [66]. In addition, 
whether VR will cause dizziness and discomfort in the experience is usually related to the matching of content interaction.

The research emphasizes VR-based, NPL-enabled chatbot system for intelligent and user-friendly manufacturing services. For future research, many aspects can be extended, including the optimization of the chatbot engine, the design of VR interactive scenarios, and the integration of the chatbot knowledge base and building of a broader spectrum of corporate domain knowledge. Among these, the last one is the most challenging task. The development of a chatbot alone is mature, but there are many novel methodologies, knowledge bases, and integrated chatbot applications to be further developed. Incorporating VR and chatbots for advanced human-computer interfaces (HCI), as demonstrated in this research, will continue to be a mainstream research direction for achieving intelligent and comprehensive manufacturing services.

Author Contributions: Conceptualization, A.J.C.T. and C.V.T.; methodology, A.J.C.T., M.-H.C., and N.-J.H.; software, M.-H.C., N.-J.H. and C.-T.W.; validation, A.J.C.T. and C.V.T.; formal analysis, M.-H.C. and N.-J.H.; investigation, M.-H.C.; resources, A.J.C.T.; data curation, N.-J.H. and C.-T.W.; writing-review and editing, A.J.C.T., C.V.T. and M.-H.C.; visualization, M.-H.C., N.-J.H. and C.-T.W.; supervision, A.J.C.T.; project administration, A.J.C.T.; funding acquisition, A.J.C.T. and C.V.T. All authors have read and agreed to the published version of the manuscript.

Funding: This research is partially supported by the Ministry of Science and Technology, Taiwan (Grant numbers: MOST-108-2221-E-007-075-MY3 and MOST-110-2221-E-007-113-MY3).

Acknowledgments: This research is partially supported by the Ministry of Science and Technology research grants (Grant numbers: MOST-108-2221-E-007-075-MY3 and MOST-110-2221-E-007-113MY3).

Conflicts of Interest: The authors declare no conflict of interest. The funders had no role in the design of the study; in the collection, analyses, or interpretation of data; in the writing of the manuscript, or in the decision to publish the results.

\section{References}

1. Ho, Y.C.; Lin, C.H. A QFD-, concurrent engineering-, and target costing-based methodology for ODM companies to formulate RFQs. J. Manuf. Technol. Manag. 2009, 20, 1119-1146. [CrossRef]

2. Bradley, A.J. Brace Yourself for an Explosion of Virtual Assistants. Available online: https://blogs.gartner.com/anthony_bradley/ 2020/08/10/brace-yourself-for-an-explosion-of-virtual-assistants/ (accessed on 24 January 2021).

3. Połap, D.; Kęsik, K.; Winnicka, A.; Woźniak, M. Strengthening the perception of the virtual worlds in a virtual reality environment. ISA Trans. 2020, 102, 397-406. [CrossRef] [PubMed]

4. CAICT; Huawei; CPCVR. White Paper on China's VR Application Status. Available online: http://www.caict.ac.cn/kxyj/qwfb/ bps/201809/P020180927353357735852.pdf (accessed on 24 January 2021).

5. Winders, J. Power Transformers: Principles and Applications; CRC Press: Boca Raton, FL, USA, 2002.

6. Trappey, A.J.C.; Trappey, C.; Govindarajan, U.H. Knowledge Extraction of RfQ Engineering Documents for Smart Manufacturing. In Proceedings of the 22nd International Conference on Advances in Materials \& Processing Technologies, Taipei, Taiwan, 20-24 October 2019.

7. Wongvasu, N. Methodologies for Providing Rapid and Effective Response to Request for Quotation (RFQ) of Mass Customization Products; Northeastern University: Boston, MA, USA, 2001.

8. Deshpande, A.; Shahane, A.; Gadre, D.; Deshpande, M.; Joshi, P.M. A survey of various chatbot implementation techniques. Int. J. Comput. Eng. Appl. 2017, 11, 1-7.

9. Bouziane, A.; Bouchiha, D.; Doumi, N.; Malki, M. Question answering systems: Survey and trends. Procedia Comput. Sci. 2015, 73, 366-375. [CrossRef]

10. Jurafsky, D.; Martin, J.H. Speech and Language Processing, 3rd ed.; draft; Stanford University: Stanford, CA, USA, 2019; Available online: https:/ / web.stanford.edu/ \{\}jurafsky/slp3/ (accessed on 24 January 2021).

11. Lokman, A.S.; Ameedeen, M.A. Modern chatbot systems: A technical review. In Proceedings of the Future Technologies Conference, Vancouver, BC, Canada, 13-14 November 2018; pp. 1012-1023.

12. Mishra, A.; Jain, S.K. A survey on question answering systems with classification. J. King Saud Univ.-Comput. Inf. Sci. 2016, 28, 345-361. [CrossRef]

13. Wu, Y.; Wu, W.; Xing, C.; Zhou, M.; Li, Z. Sequential matching network: A new architecture for multi-turn response selection in retrieval-based chatbots. arXiv 2016, arXiv:1612.01627. 
14. Xu, A.; Liu, Z.; Guo, Y.; Sinha, V.; Akkiraju, R. A new chatbot for customer service on social media. In Proceedings of the 2017 CHI Conference on Human Factors in Computing Systems, Denver, CO, USA, 6-11 May 2017; pp. 3506-3510.

15. Jang, J.; Lee, K. Transforming a Specialized Q\&A System to a Chatbot System: A Case of a Simplified Taxation in Korea Proceedings of International Conference on Human-Computer Interaction, Orlando, FL, USA, 26-31 July 2019; pp. $296-308$.

16. Gapanyuk, Y.; Chernobrovkin, S.; Leontiev, A.; Latkin, I.; Belyanova, M.; Morozenkov, O. The Hybrid Chatbot System Combining Q\&A and Knowledge-base Approaches. In Proceedings of the 7th International Conference on Analysis of Images, Social Networks and Texts, Moskow, Russia, 5-7 July 2017; pp. 42-53.

17. Nayak, S.P.; Rai, A.; Vankataramanappa, K.; Pansuriya, J.A.; Singler, J. Adaptive MoD Chatbot: Toward Providing Contextual Corporate Summarized Document as Suggestions and Reported Issue Ticket Routing. In Advances in Artificial Intelligence and Data Engineering; Springer: Berlin/Heidelberg, Germany, 2021; pp. 659-674.

18. Chao, M.-H.; Trappey, A.J.C.; Wu, C.-T. Emerging Technologies of Natural Language-Enabled Chatbots: A Review and Trend Forecast Using Intelligent Ontology Extraction and Patent Analytics. Complexity 2021, 2021, 5511866. [CrossRef]

19. Hong, N.J.; Govindarajan, U.H.; Chang Chien, J.C.; Trappey, A.J.C. Comprehensive Technology Function Product Matrix for Intelligent Chatbot Patent Mining. In Proceedings of the 2019 IEEE International Conference on Systems, Man and Cybernetics (SMC), Bari, Italy, 6-9 October 2019; pp. 1344-1348.

20. Chowdhury, G.G. Natural language processing. Annu. Rev. Inf. Sci. Technol. 2003, 37, 51-89. [CrossRef]

21. Ganguly, D.; Roy, D.; Mitra, M.; Jones, G.J. Word embedding based generalized language model for information retrieval. In Proceedings of the 38th International ACM SIGIR Conference on Research and Development in Information Retrieval, Santiago, Chile, 9-13 August 2015; pp. 795-798.

22. Turian, J.; Ratinov, L.; Bengio, Y. Word representations: A simple and general method for semi-supervised learning. In Proceedings of the 48th Annual Meeting of the Association for Computational Linguistics, Stroudsburg, PA, USA, 11-16 July 2010; pp. 384-394.

23. Bengio, Y.; Ducharme, R.; Vincent, P.; Jauvin, C. A neural probabilistic language model. J. Mach. Learn. Res. 2003, 3, $1137-1155$.

24. Mikolov, T.; Sutskever, I.; Chen, K.; Corrado, G.S.; Dean, J. Distributed representations of words and phrases and their compositionality. Adv. Neural Inf. Processing Syst. 2013, 26, 3111-3119.

25. Burdea, G.C.; Coiffet, P. Virtual Reality Technology; John Wiley \& Sons: Hoboken, NJ, USA, 2003.

26. Bamodu, O.; Ye, X.M. Virtual reality and virtual reality system components. In Advanced Materials Research; Atlantis Press: Paris, France, 2013; pp. 1169-1172.

27. Chiariotti, F. A Survey on 360-Degree Video: Coding, Quality of Experience and Streaming. arXiv 2021, arXiv:2102.08192. [CrossRef]

28. Hayes, B.; Chang, Y. Lightweight Evolving 360 VR Adaptive Video Delivery. In Proceedings of the 2020 International Conference on Computing, Networking and Communications (ICNC), Big Island, HI, USA, 17-20 February 2020; pp. 815-819.

29. Corbillon, X.; de Simone, F.; Simon, G. 360-degree video head movement dataset. In Proceedings of the 8th ACM on Multimedia Systems Conference, Taipei, Taiwan, 20-23 June 2017; pp. 199-204.

30. Mirzaei, M.; Kán, P.; Kaufmann, H. Effects of Using Vibrotactile Feedback on Sound Localization by Deaf and Hard-of-Hearing People in Virtual Environments. Electronics 2021, 10, 2794. [CrossRef]

31. Iida, K. Head-Related Transfer Function and Acoustic Virtual Reality; Springer: Berlin/Heidelberg, Germany, 2019.

32. Hong, D.; Lee, T.-H.; Joo, Y.; Park, W.-C. Real-time sound propagation hardware accelerator for immersive virtual reality 3D audio. In Proceedings of the 21st ACM SIGGRAPH Symposium on Interactive 3D Graphics and Games, San Francisco, CA, USA, 25-27 February 2017; pp. 1-2.

33. Rietzler, M.; Geiselhart, F.; Frommel, J.; Rukzio, E. Conveying the Perception of Kinesthetic Feedback in Virtual Reality using State-of-the-Art Hardware. In Proceedings of the 2018 CHI Conference on Human Factors in Computing Systems, Montreal QC, Canada, 21-26 April 2018.

34. Nam, S.; Kwon, J. Virtual Reality Interface for Visual Art with a Five-Fingered Haptic Controller. In Proceedings of the 2020 3rd International Conference on Image and Graphics Processing, Singapore, 8-10 February 2020; pp. 101-105.

35. Kim, Y.M.; Rhiu, I.; Rhie, M.; Choi, H.S.; Yun, M.H. Current State of User Experience Evaluation in Virtual Reality: A Systematic Review from an Ergonomic Perspective. In Proceedings of the Human Factors and Ergonomics Society Annual Meeting; Sage Publications: Los Angeles, CA, USA, 2019; pp. 1274-1275.

36. Hamid, N.S.S.; Aziz, F.A.; Azizi, A. Virtual reality applications in manufacturing system. In Proceedings of the 2014 Science and Information Conference, London, UK, 27-29 August 2014; pp. 1034-1037.

37. Gonzalez-Badillo, G.; Medellin-Castillo, H.I.; Lim, T. Development of a haptic virtual reality system for assembly planning and evaluation. Procedia Technol. 2013, 7, 265-272. [CrossRef]

38. Peng, G.; Wang, G.; Liu, W.; Yu, H. A desktop virtual reality-based interactive modular fixture configuration design system. Comput. Aided Des. 2010, 42, 432-444. [CrossRef]

39. Guo, Z.; Zhou, D.; Zhou, Q.; Mei, S.; Zeng, S.; Yu, D.; Chen, J. A hybrid method for evaluation of maintainability towards a design process using virtual reality. Comput. Ind. Eng. 2020, 140, 106227. [CrossRef]

40. Nee, A.Y.; Ong, S.-K. Virtual and augmented reality applications in manufacturing. IFAC Proc. Vol. 2013, 46, 15-26. [CrossRef]

41. Wang, W.; Wong, S.S.-1.; Lai, F.H.-y. The Effect of Virtual Reality Rehabilitation on Balance in Patients with Parkinson's Disease: A Systematic Review and Meta-Analysis. Electronics 2021, 10, 1003. [CrossRef] 
42. Schuster, A.; Larsen, L.; Fischer, F.; Glück, R.; Schneyer, S.; Kühnel, M.; Kupke, M. Smart manufacturing of thermoplastic cfrp skins. Procedia Manuf. 2018, 17, 935-943. [CrossRef]

43. Woo, J.H.; Oh, D. Development of simulation framework for shipbuilding. Int. J. Comput. Integr. Manuf. 2018, 31, 210-227. [CrossRef]

44. $\mathrm{Wu}, \mathrm{W}$.; Shao, X.; Liu, H. Automatic visibility evaluation method for application in virtual prototyping environment. Int. J. Comput. Integr. Manuf. 2019, 32, 960-978. [CrossRef]

45. Lau, K.W. Organizational learning goes virtual? A study of employee's learning achievement in stereoscopic 3D virtual reality Learn. Organ. 2015, 22, 289-303. [CrossRef]

46. Mora-Serrano, J.; Rivera, M.-L.; Valero, I. Factors for the Automation of the Creation of Virtual Reality Experiences to Raise Awareness of Occupational Hazards on Construction Sites. Electronics 2021, 10, 1355. [CrossRef]

47. Yang, X.; Malak, R.C.; Lauer, C.; Weidig, C.; Hagen, H.; Hamann, B.; Aurich, J.C.; Kreylos, O. Manufacturing system design with virtual factory tools. Int. J. Comput. Integr. Manuf. 2015, 28, 25-40. [CrossRef]

48. Berni, A.; Borgianni, Y. Applications of virtual reality in engineering and product design: Why, what, how, when and where Electronics 2020, 9, 1064. [CrossRef]

49. Arrighi, P.-A.; Mougenot, C. Towards user empowerment in product design: A mixed reality tool for interactive virtual prototyping. J. Intell. Manuf. 2019, 30, 743-754. [CrossRef]

50. Velasquez, A.C. Examining Virtual Reality As An Empathizing Tool For Early Ideation Stage in Design. Available online: http:/ / hdl.handle.net/1853/62552 (accessed on 1 May 2020).

51. Malik, A.A.; Brem, A. Digital twins for collaborative robots: A case study. arXiv 2020, arXiv:2006.08760.

52. Lipton, J.I.; Fay, A.J.; Rus, D. Baxter's Homunculus: Virtual Reality Spaces for Teleoperation in Manufacturing. IEEE Robot. Autom. Lett. 2018, 3, 179-186. [CrossRef]

53. Han, Y.-S.; Lee, J.; Lee, J.; Lee, W.; Lee, K. 3D CAD data extraction and conversion for application of augmented/virtual reality to the construction of ships and offshore structures. Int. J. Comput. Integr. Manuf. 2019, 32, 658-668. [CrossRef]

54. Gorecky, D.; Khamis, M.; Mura, K. Introduction and establishment of virtual training in the factory of the future. Int. J. Comput. Integr. Manuf. 2017, 30, 182-190. [CrossRef]

55. Sermet, Y. Knowledge Generation and Communication in Intelligent and Immersive Systems: A Case Study on Flooding. Ph.D. Thesis, University of Iowa, Iowa City, IA, USA, 2020.

56. Rong, X. word2vec parameter learning explained. arXiv 2014, arXiv:1411.2738.

57. Jamison, D.C. Structured query language (SQL) fundamentals. Curr. Protoc. Bioinform. 2003, 00, 9.2.1-9.2.29. [CrossRef]

58. Lelis, A.; Vretos, N.; Daras, P. Nadine-Bot: An Open Domain Migrant Integration Administrative Agent. In Proceedings of the 2020 IEEE International Conference on Multimedia \& Expo Workshops (ICMEW), London, UK, 6-10 July 2020; pp. 1-6.

59. Bao, Q.; Ni, L.; Liu, J. HHH: An online medical chatbot system based on knowledge graph and hierarchical bi-directional attention. In Proceedings of the Australasian Computer Science Week Multiconference, Melbourne, VIC, Australia, 4-6 February 2020; pp. 1-10.

60. Carlander-Reuterfelt, D.; Carrera, Á.; Iglesias, C.A.; Araque, Ó.; Rada, J.F.S.; Muñoz, S. JAICOB: A data science chatbot. IEEE Access 2020, 8, 180672-180680. [CrossRef]

61. Mondal, A.; Dey, M.; Das, D.; Nagpal, S.; Garda, K. Chatbot: An automated conversation system for the educational domain. In Proceedings of the 2018 International Joint Symposium on Artificial Intelligence and Natural Language Processing (iSAI-NLP), Pattaya, Thailand, 15-17 November 2018; pp. 1-5.

62. Mnasri, M. Recent advances in conversational NLP: Towards the standardization of Chatbot building. arXiv 2019, arXiv:1903.09025.

63. Wickramasinghe, W.; de Saram, P.; Liyanage, C.; Rangika, L.; Ranathunga, L. Virtual reality markup framework for generating interactive indoor environment. In Proceedings of the 2017 IEEE 3rd International Conference on Engineering Technologies and Social Sciences (ICETSS), Bangkok, Thailand, 7-8 August 2017; pp. 1-6.

64. Malik, A.A.; Masood, T.; Bilberg, A. Virtual reality in manufacturing: Immersive and collaborative artificial-reality in design of human-robot workspace. Int. J. Comput. Integr. Manuf. 2020, 33, 22-37. [CrossRef]

65. Stanica, I.; Dascalu, M.-I.; Bodea, C.N.; Moldoveanu, A.D.B. VR job interview simulator: Where virtual reality meets artificial intelligence for education. In Proceedings of the 2018 Zooming Innovation in Consumer Technologies Conference (ZINC), Novi Sad, Serbia, 30-31 May 2018; pp. 9-12.

66. Liagkou, V.; Stylios, C.; Pappa, L.; Petunin, A. Challenges and opportunities in industry 4.0 for mechatronics, artificial intelligence and cybernetics. Electronics 2021, 10, 2001. [CrossRef] 